\title{
Forced and Aeroelastic Responses of Bird-Damaged Fan Blades: A Comparison and Its Implications
}

\author{
Eric R. Muir* and Peretz P. Friedmann \\ University of Michigan, Ann Arbor, Michigan 48109
}

DOI: $10.2514 / 1 . C 033424$

\begin{abstract}
The aeroelastic response of a bird-damaged fan stage at the inlet of a high-bypass ratio turbofan engine is examined using a combined computational fluid dynamics and computational structural dynamics framework. The damaged fan sector consists of five blades obtained from accurate numerical simulation of the bird impact. Forced and aeroelastic response calculations are performed and compared to assess the role of aeroelastic coupling. The calculations are performed at 100,75 , and $60 \%$ throttle settings to investigate the role of engine speed on the fan response. Results from the forced response and aeroelastic response calculations indicate that the undamaged blades opposite the damaged sector exhibit the highest level of structural response. Comparing the forced response with the aeroelastic response shows increased participation of the higher structural modes, especially for the damaged blades, that grow in time or exhibit beating. Examination of the work performed by the aerodynamic forces suggests that the growth in blade response is due to aeroelastic phenomena and can cause a potential instability. The results illustrate the importance of aeroelastic effects when predicting the post-bird-strike fan response.
\end{abstract}

\section{Nomenclature}

C = radial basis function interpolant coefficient vector

$D=$ number of radial basis function driver points

$\boldsymbol{F}_{\text {aero }}=$ assembled aerodynamic force vector

$\boldsymbol{F}_{\Omega}=$ assembled centrifugal force vector

$K=$ global structural stiffness matrix

$M \quad=\quad$ global structural mass matrix

$\dot{m}=$ mass flow rate

$\dot{m}_{R}=$ referred mass flow rate

$\boldsymbol{n}=$ element normal vector

$P \quad=$ aerodynamic total pressure

$P R \quad=$ total pressure ratio

$p=$ aerodynamic static pressure

$\boldsymbol{Q}^{j} \quad=$ aerodynamic force vector on $j$ th node of computational fluid dynamics mesh

$q_{m} \quad=\quad$ generalized degree of freedom of the $m$ th mode

$S=$ computational fluid dynamics element surface area

$T=$ aerodynamic total temperature

$t=$ time

$\boldsymbol{U}=$ assembled nodal displacement vector

$W_{\mathrm{AR}}=$ aerodynamic work from aeroelastic calculations

$W_{\mathrm{FR}}=$ aerodynamic work from forced response calculations

$\boldsymbol{x}=$ nodal position vector

$\boldsymbol{x}^{d} \quad=$ radial basis function driver point

$\boldsymbol{x}^{e}=$ radial basis function evaluation point

$\Gamma \quad=$ computational fluid dynamics mesh diffusivity

$\boldsymbol{\delta}=$ computational fluid dynamics mesh displacement

$\Lambda=$ computational fluid dynamics element volume

$\Lambda_{\text {ref }}=$ reference computational fluid dynamics element volume

$\boldsymbol{\varsigma}=$ $\begin{array}{ll}\hat{\boldsymbol{\xi}} & =\begin{array}{l}\text { radial basis function interpolant of the computational } \\ \end{array} \\ \tau & =\text { fluid dynamics mesh deformation } \\ \phi & =\text { radial basis function } \\ \boldsymbol{\Phi}_{m} & =\text { mode shape deformation of the } m \text { th mode } \\ \Omega & =\text { engine rotation speed }\end{array}$

Subscripts

$m=$ mode number

STD $=$ standard atmosphere conditions

Superscripts

$j \quad=\quad$ reference to node $j$ in the computational fluid dynamics

mesh

( ) $\quad=\mathrm{d} / \mathrm{d} t$; differentiation with time

\section{Introduction}

B IRD strike on jet engine fan blades is important for the design of both civilian and military aircraft. Bird strikes occur primarily during takeoff and landing due to the tendency of birds to congregate in the vicinity of the ground [1]. The low altitude at which bird strikes occur limits recovery options and enhances the risk due to bird strike. The turbofan engines used in commercial and military aircraft have a large intake area covered by fan blades that increases the chance of bird strikes. During bird strike, the bird hits the fan blades, fragments, and propagates through the engine core and bypass duct. The impact can cause substantial deformation of the blade leading edge over a large region of the blade span, accompanied by global bending and twist of the blade [2]. Furthermore, the thin low-aspect-ratio lowcamber fan blades used in modern turbofans are structurally and aerodynamically optimized for efficiency at normal operating conditions, and bird damage induces offdesign operation [3].

The Federal Aviation Administration (FAA) mandates comprehensive standards for bird-strike resistance. Engine certification requires successful demonstration of compliance with Federal Aviation Regulation Code of Federal Regulation 33.76 in which a bird is fired with an air cannon at a test stand mounted, running engine [4]. For a modern, commercial turbofan engine, three tests are mandated: the single large bird impact test, the medium flocking bird test, and the single largest medium bird test. The single large bird impact test verifies that an engine can be safely shutdown after ingestion of a $6 \mathrm{lb}(2.72 \mathrm{~kg})$ bird without endangering the airworthiness of the aircraft. The aerodynamic and aeroelastic response of the damaged fan is not a factor for single large bird tests, since there exist no 
requirements for continued operation after ingestion. The medium flocking bird test simulates a flock encounter and requires ingestion of one $2.5 \mathrm{lb}(1.13 \mathrm{~kg})$ bird and three $1.5 \mathrm{lb}(0.68 \mathrm{~kg})$ birds. The $2.5 \mathrm{lb}$ bird is aimed at the flowpath leading to the core duct, one of the $1.5 \mathrm{lb}$ birds is aimed at the most critical exposed location of the fan as determined by the engine manufacturer, and the remaining $1.5 \mathrm{lb}$ birds are evenly distributed over the engine face. The single largest medium bird test requires ingestion of a $2.5 \mathrm{lb}$ bird at the most critical location outboard of the flowpath leading to the core duct. The damaged engines from the medium bird tests must maintain $75 \%$ of the maximum rated thrust and meet engine handling requirements for a series of post-bird-strike operating conditions that simulate an emergency landing sequence. Figure 1 provides a throttle skyline chart that describes the sequence of throttle settings for the run-on demonstration.

Assuming the fan blades withstand the initial impact, the minimum thrust requirement and run-on demonstration of the medium bird tests are particularly challenging. Aerodynamic disturbances caused by the bird damage, such as flow separation, vortex shedding, and shock oscillations, can result in sustained thrust loss. These aerodynamic disturbances also introduce significant unsteady aerodynamic forces that can lead to high levels of vibratory stress and eventual fatigue failure of the blades during the run-on demonstration. Furthermore, the unsteady aerodynamic forces can couple with the structural dynamics to produce a complex aeroelastic response problem that can lead to aeroelastic instability [5,6]. Predicting the aeroelastic behavior of a bird-damaged fan blade represents a significant design barrier in the development of improved-efficiency turbofan engines [1].

Numerical simulations provide a cost-effective means for assessing the aerodynamic loading and aeroelastic behavior of a damaged fan. However, the combined aerodynamic and structural dynamic modeling of a bird-damaged fan assembly, where the damage is typically limited to a sector of blades, is a complex problem. Computational structural dynamics (CSD) based on the finite element method (FEM) are typically used to model the bird impact and resulting structural response, since it can represent complex material behavior and nonlinear geometric deformations [7-13]. Computational fluid dynamics (CFD) is required to accurately capture the complex flow phenomena associated with bird-damaged turbofans [14-17]. Reliable CSD and CFD methods exist to compute the bird impact, structural dynamic response, and unsteady aerodynamic loads of a damaged fan blade. However, due to the computational times required for CFD methods, the structural and aerodynamic computations are typically performed separately in an uncoupled manner. Therefore, the aeroelastic effects that may be important in the bird-strike problem are not properly accounted for.

Two primary methods are used to couple the CSD and CFD components: the classical approach, which ignores the interaction between the fluid and structure; and the integrated approach, which attempts to account for it. Forced response calculations use a classical or one-way coupled approach to calculate the effect of the unsteady flowfield on the structural response [17-19]. In this approach, the aerodynamic calculations are performed first for a rigid geometry. Subsequently, the unsteady aerodynamic forces are extracted and applied on the structural dynamic model of the blade. The aerodynamic model is not affected by the structural response; thus, the feedback mechanism of the structural response on the unsteady aerodynamic loading is not captured. In contrast, aeroelastic response calculations are performed using an integrated or two-way coupled approach that combines the aerodynamic and structural dynamic models and fully captures the aeroelastic behavior [17-20].

Despite its importance, only a limited number of computational studies have considered the aerodynamic behavior and aeroelastic response of a bird-damaged fan. Bohari and Sayma [21] presented a CFD approach for analyzing the aerodynamic characteristics of a bird-damaged NASA rotor 67 containing a single blade with assumed leading-edge damage. The steady-state CFD results conclude that the stall margins deteriorate for the damaged fan, with stall occurring below the design operating line. Imregun and Vahdati [14] and Kim et al. [15] conducted two unique studies that examined the aeroelastic response and stability of a bird-damaged bladed disk containing two damaged blades using a fully coupled CSD/CFD formulation to determine the time-dependent response. In [14], the fully coupled analysis demonstrates instability of the first torsion mode of a damaged blade; however, it is unclear if the growth in modal displacement is the result of a flutter mechanism or the strong wake shed by the upstream damaged blade. These findings are inconclusive, since the fully coupled calculations were only performed for one-third of a fan revolution due to limitations on the available computer resources. In a follow-up study [15], the aeroelastic stability was also found to be sensitive to flight conditions with flutter margins reduced at lowpressure ratios and rotating stall occurring at high-pressure ratios.

These studies provided insight into the aerodynamic behavior and aeroelastic response of a bird-damaged fan. However, the damaged sector was limited to one or two blades, and the form of the damage did not resemble a configuration resulting from bird-strike certification tests. Furthermore, the aeroelastic response calculations of $[14,15]$ were performed at $70 \%$ engine rotational speed, and the aeroelastic behavior of the damaged fan at other engine speeds was not considered. Therefore, it is evident that a computational aeroelastic study of a bird-damaged commercial turbofan, with damage representative of experimental bird-strike tests or accurate numerical simulation of the bird-strike event, is required to improve our fundamental understanding of the bird-strike problem.

In [22], the authors presented an aerodynamic model that is capable of capturing the behavior of a damaged fan sector of a commercial turbofan engine and is suitable for modeling both the forced and aeroelastic responses of the bird-damaged blades. Subsequently, in [23], the aerodynamic model and a structural dynamic model were combined to produce the forced response behavior so as

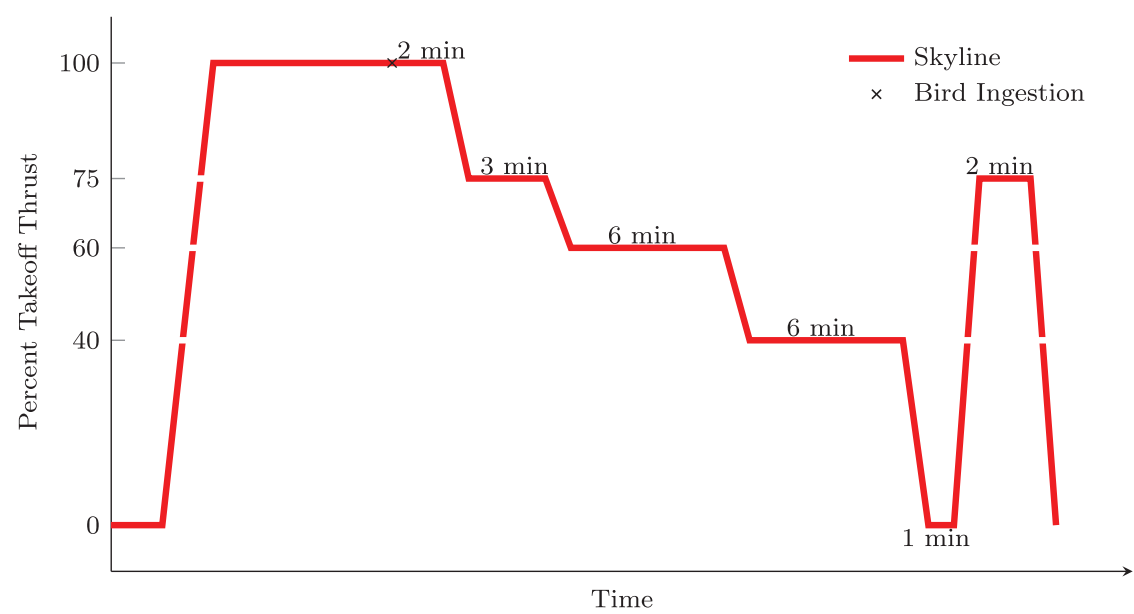

Fig. 1 Throttle skyline chart for run-on demonstration. 


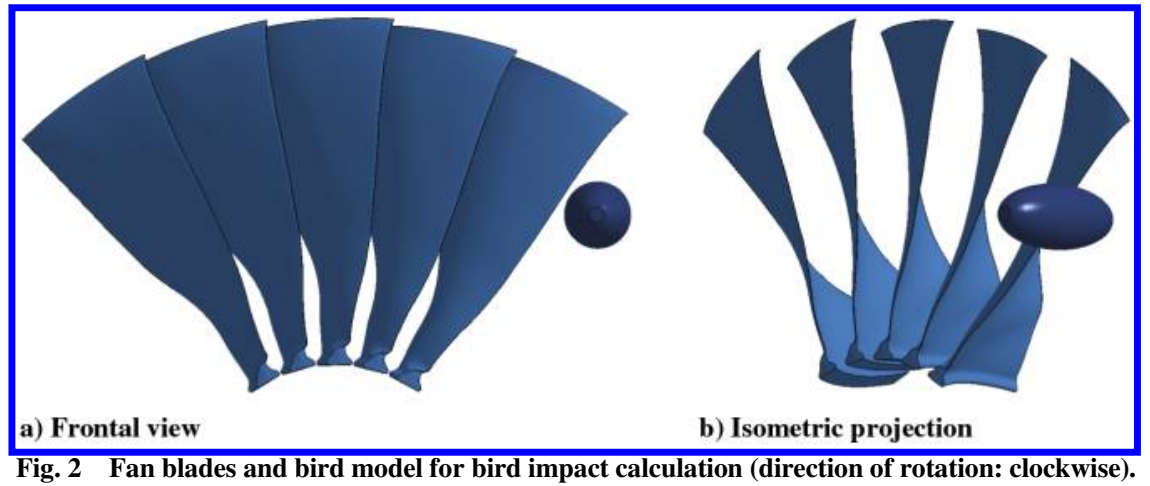

to gain insight into this complex system. In [24], the forced response framework was extended to accommodate two-way coupling between the aerodynamic and structural dynamic models of the birddamaged fan and preliminary aeroelastic response calculations were performed. In this paper, the combined CFD and CSD framework is implemented to compare the blade response resulting from one-way forced response and fully coupled aeroelastic response calculations, and thus assess the role of complete aeroelastic coupling on the response. The calculations were performed at the 100,75 , and $60 \%$ throttle settings, on the skyline chart in Fig. 1, to examine the effect of engine speed on the fan response. The specific objectives of the current study are as follows:

1) Present a coupled CFD/CSD framework for one-way forced response and fully coupled aeroelastic response calculations of a bird-damaged fan.

2) Study in detail the forced and aeroelastic responses of a birddamaged turbofan stage with damage that is representative of an experimental bird strike involving a sector of five blades. Perform the computations at 100,75 , and $60 \%$ throttle settings as required by the FAA, thus exploring the entire operating envelope of the engine.

3) Compare the blade response resulting from one-way forced response and fully coupled aeroelastic response calculations to assess the importance of complete aeroelastic coupling in predicting the post-bird-strike fan response.

4) Compare the aerodynamic work calculated from the forced and aeroelastic response calculations to identify the potential for aeroelastic instability.

It is important to emphasize that $[14,15]$ assumed two damaged blades in the fan that was operating at a $7 \overline{0 \%}$ engine rotational speed. In [14], the computations were also performed at $70 \%$ engine speed and only one-third of a revolution was considered due to limitations on computational resources. Thus, the present study makes several original contributions that have not been published in the available literature on bird strike.

\section{Damaged Fan Configuration}

The LS-DYNA code is used to simulate the bird impact and obtain the bird-damaged configuration. The LS-DYNA code has been extensively used to model bird-strike problems and has proven itself a reliable tool for computing the damaged blade configurations $[7,13]$. The turbofan geometry examined in this study resembles a modern, commercial high-bypass ratio turbofan engine with an inlet diameter of approximately $55 \mathrm{in} .(1.4 \mathrm{~m})$. The single largest medium bird test often results in the most substantial damage, since the $2.5 \mathrm{lb}$ bird impacts the blade at an outer span location. Therefore, the bird-strike conditions for the LS-DYNA analysis correspond to the single largest medium bird test in which a single $2.5 \mathrm{lb}$ bird is ingested at takeoff conditions with an impact velocity of $270 \mathrm{ft} / \mathrm{s}(82.4 \mathrm{~m} / \mathrm{s})$ and a strike location of $70 \%$ blade span.

The LS-DYNA bird-strike simulation computes a typical birdstrike experimental test sequence performed in vacuum. The test sequence consists of several steps: spin the fan stage at a specified engine rotational speed, fire a bird at the fan stage, continue to spin the engine until the transient response of the blades subsides, and slow the fan stage to zero engine rotational speed. The calculation is restricted to a sector consisting of five blades cantilevered at the root, and the remaining blades are assumed to be undamaged. The fan blades are titanium and are modeled as an elastoplastic material with a piecewise linear stress-strain relationship where the yield stress is dependent on the strain rate. The bird model is an ellipsoid and uses a Lagrangian formulation. A viscous material model with erosion in tension and compression is employed to capture the impact properties of the bird. Figure 2 depicts a frontal view and isometric projection of the five fan blades and bird model used in the bird impact calculation.

Figure 3 a shows the damaged fan configuration, where the damaged blades are highlighted in orange and the blades are numbered. The blade damage includes substantial leading-edge deformation in all five blades, as well as global bending and twist. Furthermore, the damage covers a significant portion of the blade span, with the largest deforma-

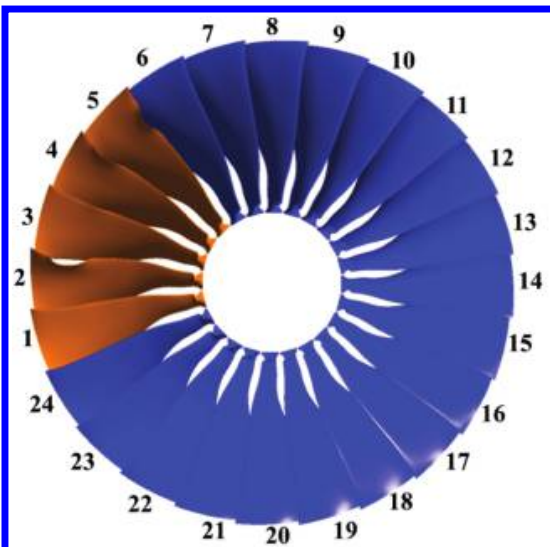

a) Bird-damaged fan configuration

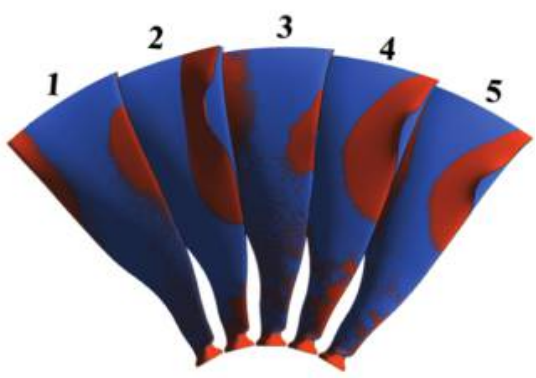

b) Comparison of damaged and undamaged blades

Fig. 3 Bird-damaged fan resulting from the bird-impact simulation (direction of rotation: clockwise). 
tion occurring for blade 2. Figure $3 \mathrm{~b}$ depicts the five undamaged blades (colored in blue) overlaid with the five damaged blades (colored in orange).

\section{Aerodynamic Model}

The ANSYS CFX commercial aerodynamic solver is used to model the compressible unsteady flow governed by the Reynoldsaveraged Navier-Stokes equations [25]. ANSYS CFX uses a finite volume approach that yields a near-second-order accurate spatial discretization and minimizes numerical reflections at the boundaries. A second-order-accurate backward Euler time-integration scheme is used for the unsteady calculations. The fluid is assumed to be ideal and calorically perfect. The $k-\epsilon$ turbulence model, which is an industry standard eddy viscosity model, is employed due to its compatibility with scalable wall functions used to efficiently resolve the near-wall boundary layer. Other two-equation turbulence models, such as the $k-\omega$ and shear-stress transport models, may capture flow separation more accurately; however, the near-wall discretization required by these models prohibited their practical use in this study. Further details of the aerodynamic model are available in [26].

The CFD calculation is restricted to an isolated fan stage suitable for prediction of the unsteady aerodynamic characteristics of a birddamaged fan. The fan stage starts downstream of the engine inlet, extends into the bypass duct and core duct, and includes a set of fan blades, a rotating hub, a stationary shroud, and a stationary splitter, as illustrated by Fig. 4. A clearance between the blade tip and shroud is specified to accurately account for the influence of the tip gap on flow losses and shock structure.

At the domain inflow, the total pressure, total temperature, turbulence intensity, and direction of the incoming flow are enforced. The mass flow rate is specified at the core duct outflow with the assumption that the engine core pulls a fixed mass flow rate through the core duct for a given engine rotation speed. The average static pressure is enforced at the bypass duct outflow using a radialequilibrium condition that permits the static pressure to vary radially and minimizes physical reflections. For the unsteady calculations, ANSYS CFX uses a nonreflective condition at the domain outflow to minimize reflection of acoustic waves $[27,28]$. Solid wall boundary conditions are enforced at the fan blades, hub, shroud, and splitter, such that the velocity of the flow matches that of the wall through specification of a no-slip condition. A zero wall velocity is prescribed at the shroud and splitter, and a nonzero wall velocity that results from engine rotation is prescribed at the blades and hub.

\section{A. Operating Condition}

The operating point of a fan stage is characterized by the total pressure ratio and referred mass flow rate. The total pressure ratio is defined as the ratio of the mass flow averaged total pressure at the bypass duct outflow to the mass flow-averaged total pressure just

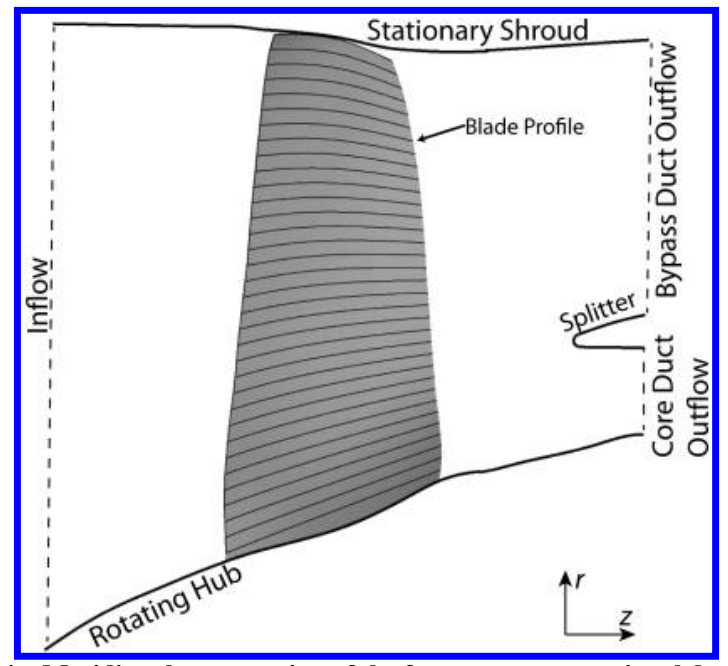

Fig. 4 Meridional cross section of the fan stage computational domain. upstream of the fan blades. The referred mass flow rate, calculated using Eq. (1), is the mass flow rate through the domain corrected for nonstandard day inflow conditions and represents the mass flow that would pass through the fan if the inflow total pressure and total temperature corresponded to standard day conditions:

$$
\dot{m}_{R}=\dot{m} \sqrt{\frac{T}{T_{\mathrm{STD}}}}\left(\frac{P_{\mathrm{STD}}}{P}\right)
$$

A fan map depicts the operating points of an isolated fan stage for a variety of operating conditions. The operating points obtained at a fixed engine speed are connected to form characteristic curves. The stall point is identified by the peak in total pressure ratio along a characteristic curve and indicates the onset of stall. Stall is an undesirable, unsteady flow phenomena produced by flow separation that typically occurs at low mass flow rates and high-bypass duct static pressure. A stall line connects the stall points on each characteristic curve and identifies the boundary of steady flow, where operating points to the left of the stall line are unsteady. A fan map also includes the fan operating line that consists of the unique set of operating points produced by the fan stage when installed in a complete engine. A representative fan map that includes an operating line, several characteristic curves, and the associated stall points is shown in Fig. 5.

The operating points at the intersection of the operating line and the characteristic curves are significant because they represent operation of the isolated fan stage in a complete engine. The bypass duct static pressure boundary condition is specified so that the predicted operating point coincides with a point on the operating line. The bypass duct static pressure necessary to achieve the desired operating point at the intersection of the characteristic curve and the operating line is unknown a priori. Therefore, an iterative procedure is used to map the characteristic curve and determine the bypass duct static pressure that yields an operating point within $\sim 3 \%$ error of the operating line. The error is calculated using Eq. (2) where the predicted operating point is denoted by $\left(\overline{\dot{m}}_{R}, \overline{P R}\right)$; and $\Delta \bar{m}_{R}$ and $\Delta P R$ denote the horizontal and vertical distance of the operating point from the operating line, as shown in Fig. 5:

$$
\% \Delta \mathrm{OL}=\sqrt{\left(\frac{\Delta \dot{m}_{R}}{\overline{\dot{m}}_{R}}\right)^{2}+\left(\frac{\Delta P R}{\overline{P R}}\right)^{2}} \times 100
$$

\section{B. Computational Mesh}

The ANSYS TurboGrid program is employed to generate a highquality structured CFD mesh of hexahedral elements for an undamaged blade passage. Proper resolution of the boundary layer and

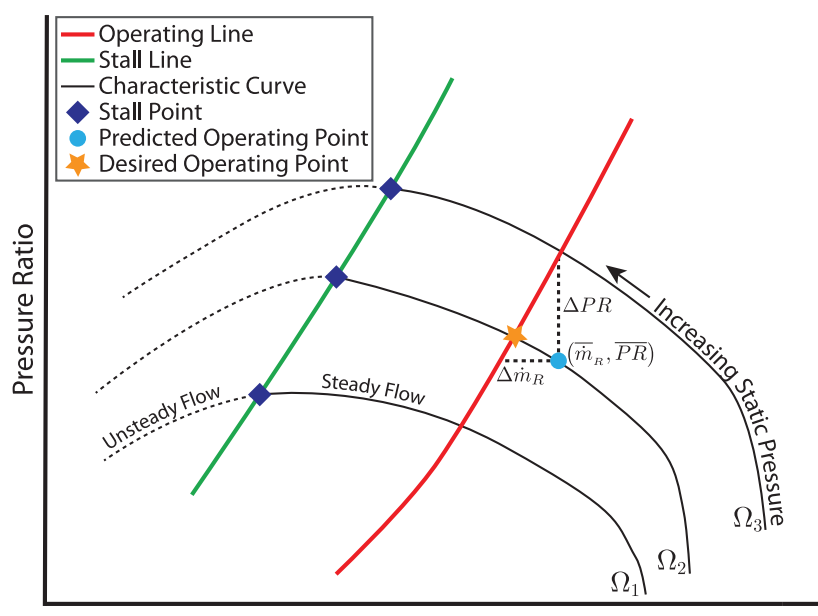

Referred Mass Flow

Fig. 5 Representative fan map. 


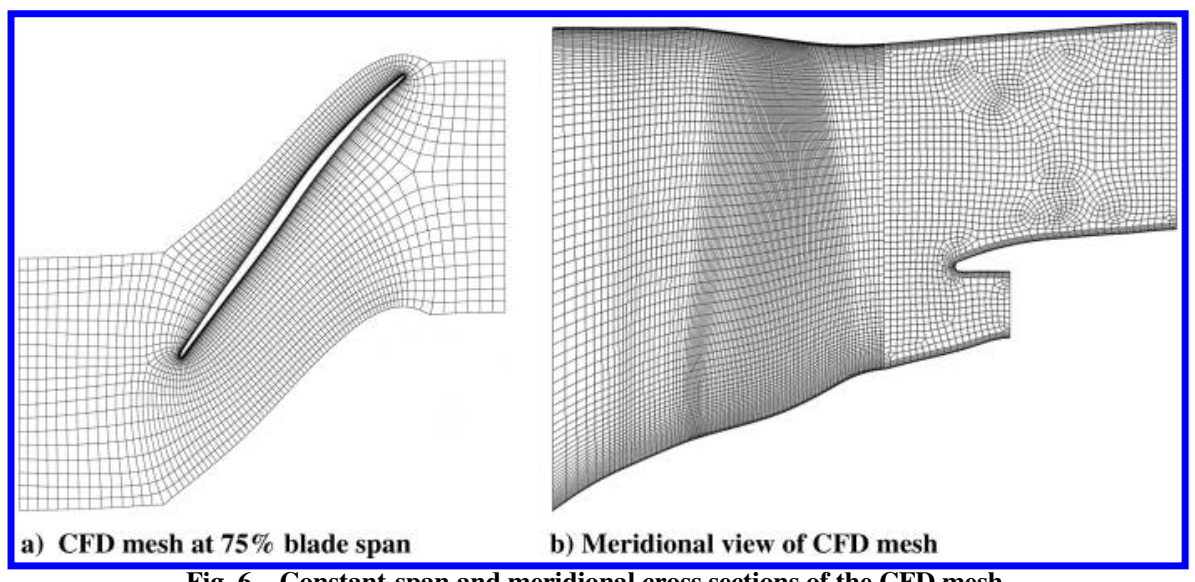

Fig. 6 Constant-span and meridional cross sections of the CFD mesh.

tip gap is essential to capture the shock structure and flow losses due to viscosity in the boundary layer and flow leakage through the tip gap. In [26], three mesh resolutions were considered: coarse, medium, and fine. The overall topology of the coarse, medium, and fine meshes corresponds to the CFD mesh in Figs. $6 \mathrm{a}$ and $6 \mathrm{~b}$. The primary difference between the three meshes is the boundary-layer refinement and tip gap resolution. Table 1 lists the number of nodes in each CFD mesh; the number of nodes in the radial direction between the blade tip and the shroud; and the minimum, maximum, and area-averaged $y+$ values of the first node from the blade surface.

The ANSYS TurboGrid topology is not applicable for full wheel geometries that include a set of damaged blades. To extend the high mesh quality produced by the ANSYS TurboGrid mesh topology to the damaged fan geometry, the automated mesh deformation scheme presented in [26] is used. This procedure employs a radial basis function network (RBFN) to interpolate the deformation field of the bird-damaged blades to the CFD mesh of the undamaged wheel. RBFN interpolation is an effective tool for multivariate interpolation and has been successfully used for large-amplitude mesh deformation in aeroelastic applications and CFD-based aerodynamic shape optimization studies [29-34].

A RBFN consists of a linear combination of radial basis functions (RBFs) used to map the deformation prescribed at the fluid domain boundaries to the interior CFD mesh. A RBF $\phi$ is a scalar function for which the value depends only on the distance from the evaluation point $\boldsymbol{x}^{e}$ to the origin, such that $\phi=\phi\left(\left\|\boldsymbol{x}^{e}\right\|\right)$. Provided a set of $D$ driver points at which the deformation is known, the RBF interpolant of the deformation field is constructed in the form given by Eq. (3). The RBF fitting coefficients $\boldsymbol{C}$ are uniquely determined by ensuring the deformation evaluated with the RBF interpolant at the driver points is equal to the prescribed deformation, as given in Eq. (4). The choice of $\mathrm{RBF}$ is important to ensure the best possible representation of the deformation field and resulting mesh quality. Reference [34] demonstrated that the volume spline defined by $\phi\left(\left\|\boldsymbol{x}^{e}\right\|\right)=\left\|\boldsymbol{x}^{e}\right\|$ is an ideal RBF for CFD mesh deformation; therefore, the volume spline is used in this study where the norm is evaluated as the Euclidean distance $\| \boldsymbol{x} e=\sqrt{x^{2}+y^{2}+z^{2}}$ :

$$
\begin{gathered}
\hat{\boldsymbol{s}}\left(\boldsymbol{x}^{e}\right)=\sum_{l=1}^{D} \boldsymbol{C}_{l} \phi\left(\left\|\boldsymbol{x}^{e}-\boldsymbol{x}_{l}^{d}\right\|\right) \\
\boldsymbol{\varsigma}_{s}=\hat{\boldsymbol{\varsigma}}\left(\boldsymbol{x}_{s}^{d}\right)=\sum_{l=1}^{D} \boldsymbol{C}_{l} \phi\left(\left\|\boldsymbol{x}_{s}^{d}-\boldsymbol{x}_{l}^{d}\right\|\right) 1 \leq s \leq D
\end{gathered}
$$

Mesh sensitivity studies were conducted in [26] for steadystate CFD calculations of the undamaged and damaged fans. It was concluded that the coarse mesh identified in [26] was sufficiently accurate for the objectives of the current study. The full wheel coarse mesh consisted of 10.4 million nodes and 9.7 million elements. Cross sections of the undamaged and damaged coarse CFD meshes at $75 \%$ span are shown in Fig. 7. The damaged fan produced by the RBF mesh deformation procedure retained the high mesh quality of the original mesh, particularly near the leading edge, as demonstrated for blade 2 in Figs. 7c and 7d.

\section{Structural Dynamic Model}

The structural dynamic model is implemented in ANSYS Mechanical APDL, which is a commercially available finite element (FE)-based structural solver that accommodates one-way and twoway coupling with ANSYS CFX for the forced and aeroelastic response calculations performed in this study. Details of ANSYS Mechanical APDL are available in ANSYS's Mechanical APDL Theory Reference Guide - Version 14.5 [35]. The computational domain for the structural dynamic model consists of 24 individual blades, with each cantilevered at the blade root. Fan blades of modern high-bypass-ratio commercial turbofans are significantly more flexible than the hub disks; therefore, the hub disk is not modeled and structural coupling between the fan blades is ignored [15]. The fan blades are titanium and are modeled with a linearly elastic, isotropic material law that neglects the residual stress and strain hardening of the damaged blades resulting from the bird impact.

\section{A. Equations of Motion}

The equations of motion are formulated from the principle of virtual work and solved by ANSYS's Mechanical APDL. The equations of motion are given by Eq. (5), where $\boldsymbol{F}_{\Omega}$ represents the centrifugal effects due to engine rotation, and $\boldsymbol{F}_{\text {aero }}$ represents the aerodynamic force transferred from the CFD mesh. The global mass and stiffness matrices are assembled for the entire structural mesh using conventional finite element methods. For simplicity of the structural dynamic model, no structural damping is implemented. The assembled displacement vector $\boldsymbol{U}$ contains the translational degrees of freedom for each node:

$$
\boldsymbol{M U}+\boldsymbol{K} \boldsymbol{U}=\boldsymbol{F}_{\Omega}+\boldsymbol{F}_{\text {aero }}
$$

Table 1 Details of the coarse, medium, and fine meshes

\begin{tabular}{lcccccccccc}
\hline \hline & & No. of tip & & & & & & & \\
Mesh & No. of nodes & nodes & Minimum $y+$ & Maximum $y+$ & Average $y+$ & $y+>2, \%$ & $y+>10, \%$ & $y+>50, \%$ & $y+>150, \%$ & $y+>250, \%$ \\
\hline Coarse & 435,546 & 4 & 1.76 & 400.86 & 101.6 & 100 & 98.1 & 73.1 & 15.0 \\
Medium & 625,485 & 9 & 0.91 & 129.0 & 24.6 & 99.2 & 81.3 & 13.8 & 0.0 \\
Fine & $1,278,743$ & 43 & 0.08 & 15.2 & 2.6 & 48.3 & 0.63 & 0.0 & 0.0 & 0.0 \\
\hline \hline
\end{tabular}




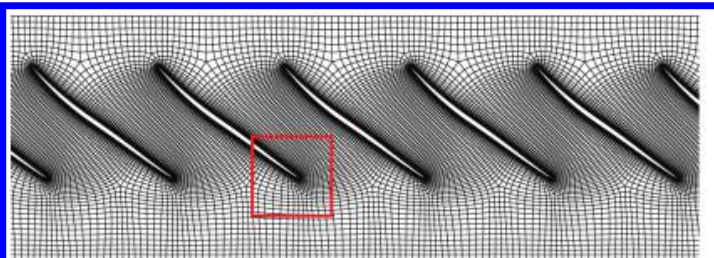

a) Undamaged CFD mesh

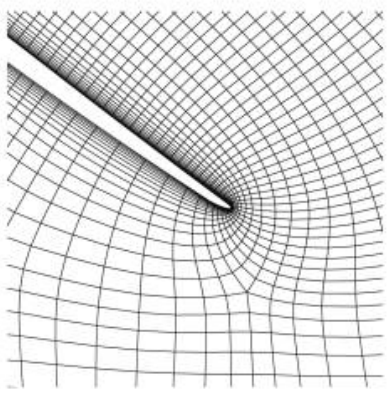

c) Undamaged blade 2

leading-edge CFD mesh

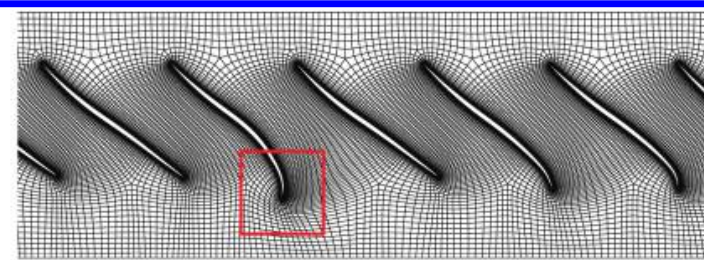

b) Damaged CFD mesh

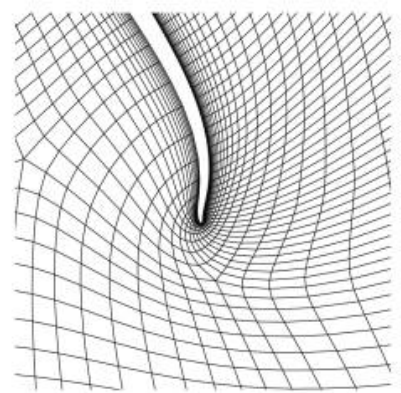

d) Damaged blade 2 leading

edge CFD mesh

Fig. 7 Comparison of the undamaged and damaged CFD meshes at $75 \%$ span.

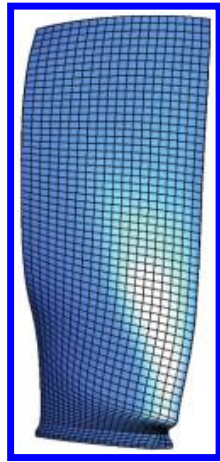

Fig. 8 Structural mesh for an undamaged blade.

The implementation of the structural dynamic model in ANSYS's Mechanical APDL includes a large deflection formulation that is limited to geometric nonlinearity. This is accomplished by a geometric stiffness matrix, where the radial loading depends on the speed of rotation and distance of the element from the axis of rotation. A Newton-Raphson iterative procedure is implemented to update the stiffness matrix within each time step. The Hilber-Hughes-Taylor (HHT)- $\alpha$ [36] time-integration scheme is used to integrate Eq. (5) in time. Further details on the Newton-Raphson algorithm and the HHT$\alpha$ scheme are available in ANSYS's Mechanical APDL Theory Reference Guide [35].

\section{B. Computational Mesh}

The fan blades are modeled using eight-noded solid, hexahedral elements (ANSYS SOLID185 element type) with three translational degrees of freedom at each node. A mesh sensitivity was conducted in [26] to identify the mesh resolution suitable for the objectives of this study. The structural mesh consists of 5712 nodes and 4020 elements per blade for a total of 137,088 nodes and 96,480 elements for the full wheel model. Figure $\underline{8}$ shows the structural mesh of an undamaged blade.

\section{Rotating Mode Shapes}

The first five mode shapes of a rotating, undamaged fan blade at a $100 \%$ takeoff engine rotational speed are shown in Fig. 9. The mode shapes of a rotating, undamaged blade at 75 and $60 \%$ takeoff thrust are similar in shape. The first five mode shapes of the damaged blades are similar to those of the undamaged blade. Differences between the mode shapes of the undamaged and damaged blades are more significant for higher-frequency modes; however, the blade responses of the damaged blades are dominated by the first five modes. Note that the frequencies and mode shapes described in Fig. 9 have been identified as first bending (1B), second bending (2B) , first torsion (1T), third bending (3B), and second torsion (2T). However, due to the built-in twist of the blade and the effect of rotation, these modes are coupled where all three degrees of freedom (bending out of the plane of rotation, bending in the plane of rotation, and torsion) participate. By identifying the mode as $1 \mathrm{~B}$, it is implied that the primary contribution to the mode shape comes from bending.

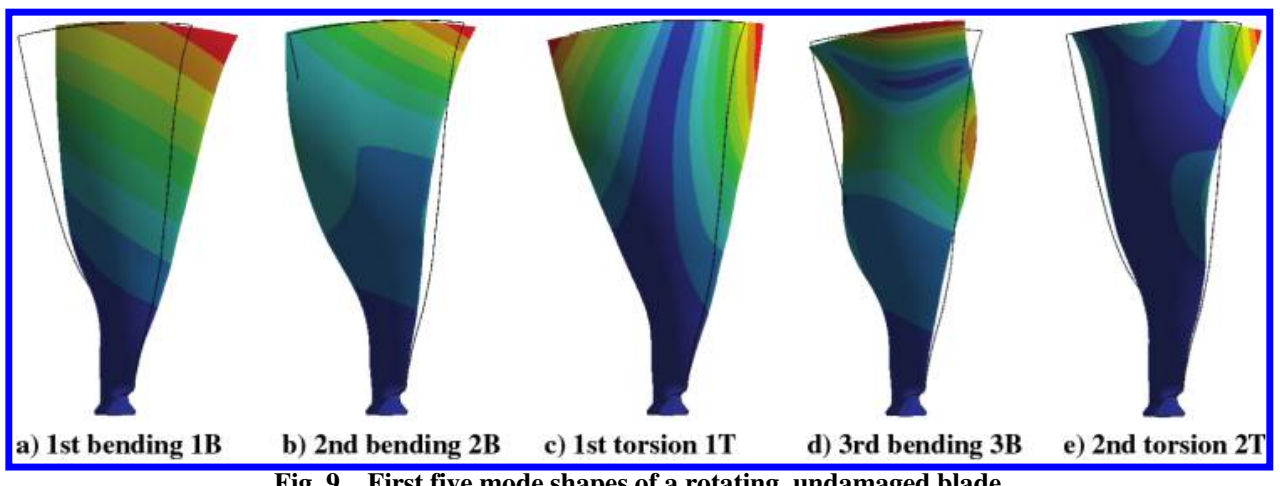

Fig. 9 First five mode shapes of a rotating, undamaged blade. 


\section{Coupled Fluid-Structure Framework}

The ANSYS multifield solver is used to couple the ANSYS CFX aerodynamic solver and ANSYS Mechanical APDL structural solver for the forced and aeroelastic response calculations performed in this study. Further details of the ANSYS multifield solver are available in ANSYS's Mechanical APDL Coupled-Field Analysis Guide [37]. The computational frameworks and coupling algorithm for the oneway and fully coupled fluid-structure interaction calculations, including the aerodynamic load transfer and mesh displacement scheme, are provided next.

\section{A. One-Way Forced Response Framework}

For one-way forced response calculations, the computed unsteady aerodynamic loads are applied to the structural model at each time step to obtain the response. For this case, the CFD mesh is not deformed as the structure deforms; therefore, the feedback mechanism of the structural response on the unsteady aerodynamic loading is not captured. The aerodynamic load for the forced response is time dependent; thus, it captures the transient nature of the aerodynamic loading. Equation (6) governs the forced response calculations:

$$
\boldsymbol{M} \ddot{\boldsymbol{U}}+\boldsymbol{K} \boldsymbol{U}=\boldsymbol{F}_{\Omega}+\boldsymbol{F}_{\text {aero }}(t)
$$

A flowchart of the forced response framework is shown in Fig. 10. The mapping between the FE mesh and the CFD mesh at the wetted surface is performed to establish the fluid-structure interface (FSI). A steady-state CFD calculation is carried out to generate the initial conditions for the unsteady CFD calculations needed for the forced response calculation. During each time step of the forced response calculation, the aerodynamic pressure and viscous loads from the unsteady CFD analysis are transferred to the surface of the FE mesh and the structural dynamic response is calculated.

\section{B. Fully Coupled Aeroelastic Framework}

To obtain the coupled fluid-structure aeroelastic response, an implicit coupling algorithm is employed where the aerodynamic and structural components representing the fan are solved iteratively in each time step. The CFD mesh is deformed with the structure such that the time-varying displacement at the blade surface influences the aerodynamic loads on the structure. The aerodynamic load varies with time due to the transient effects in the aerodynamic loading caused by both the bird damage and the blade motion. The equations governing the aeroelastic response are given by Eq. (7):

$$
\boldsymbol{M} \ddot{\boldsymbol{U}}+\boldsymbol{K} \boldsymbol{U}=\boldsymbol{F}_{\Omega}+\boldsymbol{F}_{\mathrm{aero}}(t, \boldsymbol{U}, \dot{\boldsymbol{U}}, \ddot{\boldsymbol{U}})
$$

A flowchart of the fully coupled aeroelastic framework is shown in Fig. 11. The mapping between the FE mesh and the CFD mesh is

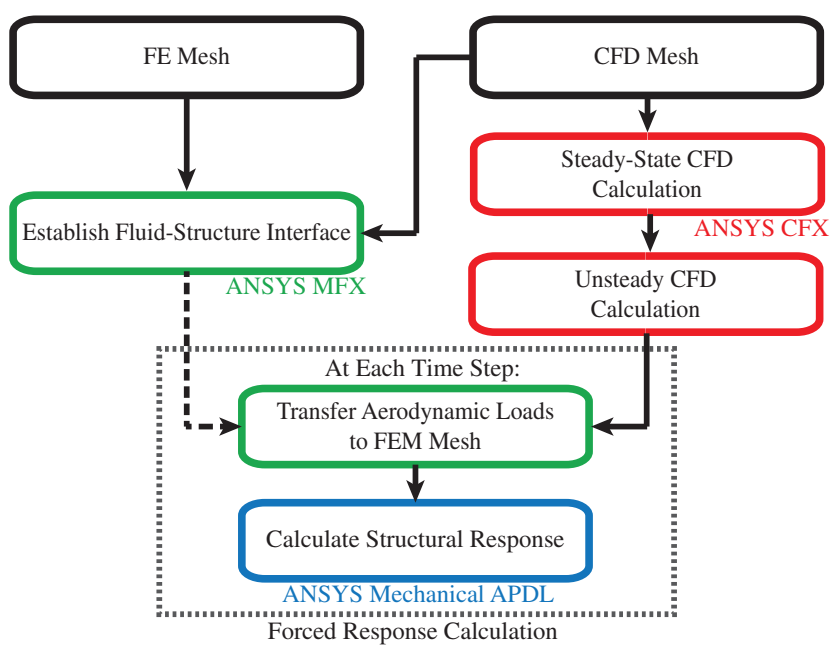

Fig. 10 Flowchart of the forced response framework.

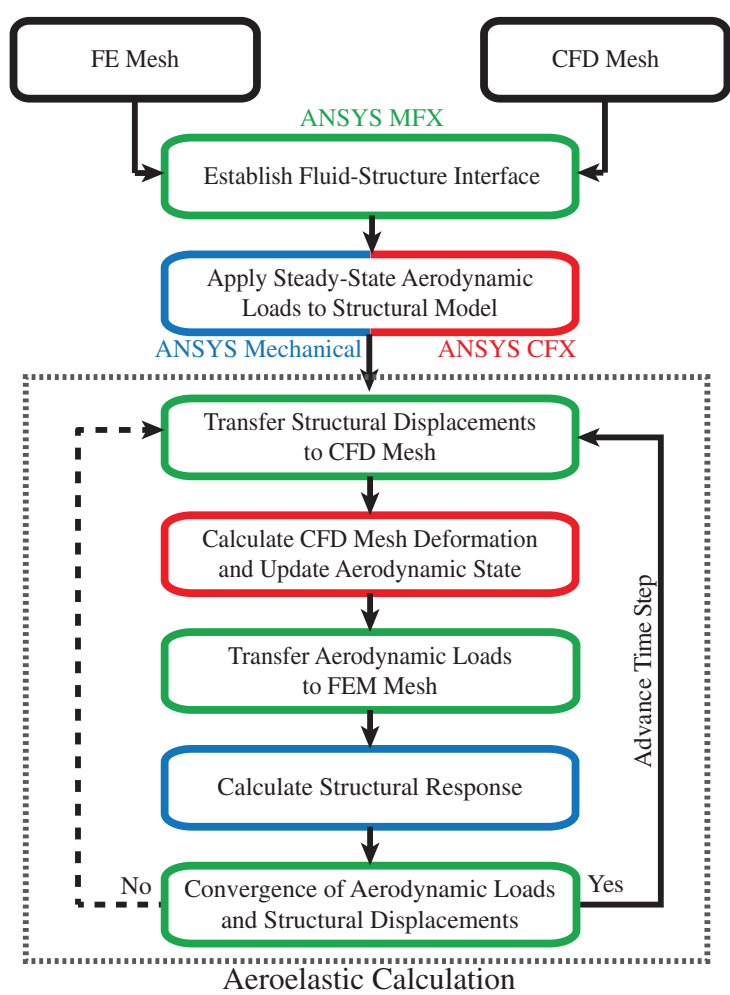

Fig. 11 Flowchart of the aeroelastic framework.

performed to establish the FSI at the wetted surface. Next, the aerodynamic forces from a steady-state CFD calculation of the damaged fan are applied to a static structural model to initialize the aerodynamic load and structural dynamic model for the aeroelastic response calculations. Within each time step of the aeroelastic response calculation, the aerodynamic state is calculated and the associated aerodynamic loads are transferred to the FE mesh. The resulting structural displacements are then transferred to the CFD mesh blade surface, and the interior CFD nodes are displaced by the amount dictated by the structural displacement.

\section{Aerodynamic Load and Structural Displacement Transfer}

The aerodynamic forces, or loads, have to be transferred from the CFD mesh to the FE mesh at the blade surface to obtain $\boldsymbol{F}_{\text {aero }}$ in Eq. (5). This is a requirement for both the forced response as well as the coupled aeroelastic calculations. The aerodynamic forces are calculated at each CFD node on the blade surface using Eq. (을 and include contributions from the aerodynamic pressure and viscous wall stresses. The forces are transferred from the CFD nodes to the FE nodes on the blade surface using the conservative interpolation scheme available in ANSYS MFX. When the blade surface on the CFD mesh and the FE mesh match exactly, the conservative interpolation scheme guarantees the conservation of the overall force transfer:

$$
\boldsymbol{Q}^{j}(t)=\int p \boldsymbol{n} \mathrm{d} S+\int \tau \mathrm{d} S
$$

For the aeroelastic calculations, the structural displacements are transferred from the FE mesh to the CFD mesh using the profilepreserving interpolation scheme available in ANSYS MFX. Each CFD node on the blade surface is mapped to a structural element on the blade surface. The shape functions of the associated FE element are used to interpolate the displacement at the corresponding CFD node. This interpolation scheme preserves the local distributions of displacements transferred from the coarser FE mesh to the finer CFD mesh.

The CFD mesh displacement is prescribed on the blade surface based on the structural displacement and is set to zero on the inlet, outlet bypass, outlet core, and splitter surfaces. The CFD nodes on the hub and shroud are permitted to slide on the boundaries so that the 
original surfaces of revolution are maintained. The displacement of the interior CFD nodes is governed by the displacement-diffusion equation provided by Eq. (9). In Eq. (9), $\Gamma$ is the mesh diffusivity, which is analogous to the mesh stiffness; and $\delta$ is the mesh displacement relative to the mesh position at the previous time step:

$$
\nabla \cdot(\Gamma \nabla \boldsymbol{\delta})=0
$$

A spatially dependent mesh diffusivity is useful for preserving the initial mesh distribution and element quality. A large mesh diffusivity restricts movement of the nodes relative to each other, with regions of lower mesh diffusivity absorbing a larger amount of the mesh displacement. A mesh diffusivity that is inversely proportional to the element volume is specified so that the larger elements in the blade passages absorb most of the displacement and the small elements near the blade surface do not become highly distorted. Equation (10) provides the expression for mesh diffusivity, where the exponent controls how quickly the mesh diffusivity changes with element volume:

$$
\Gamma=\left(\frac{\Lambda_{\mathrm{ref}}}{\Lambda}\right)^{2}
$$

\section{Results}

The steady and unsteady aerodynamic calculations of the birddamaged fan operating at the 100,75 , and $60 \%$ throttle settings are presented in this section. Subsequently, the forced response and aeroelastic response of a bird-damaged fan at these three operating conditions are presented and compared to determine the role of aeroelastic coupling. The aerodynamic work calculated from the forced response and aeroelastic response calculations are compared to identify the potential for aeroelastic instability. For brevity, the forced and aeroelastic response calculations are presented for a handful of representative blades that best illustrate the fan response. The complete set of blade responses from these calculations is provided in [26].

\section{A. Aerodynamic Calculations of the Damaged Fan}

Steady-state and unsteady aerodynamic calculations are used to provide insight into the aerodynamic characteristics of the birddamaged fan. The freestream conditions correspond to standard day $+27^{\circ} \mathrm{F}$ conditions, and the freestream flight Mach number is zero. In [26], steady-state aerodynamic calculations obtained with the CFDbased aerodynamic model were verified against results from an industry CFD solver for an undamaged fan. The aerodynamic calculations from the industry CFD solver were performed independent of this study. Reference [26] also includes a comparison of steady CFD calculations for a damaged fan with data from the industry CFD solver. Overall, steady CFD calculations showed good agreement for the complex flowfield associated with the damaged fan sector and confirm the capabilities of the aerodynamic model for this type of calculation.

\section{B. Steady-State Aerodynamic Calculations}

Steady aerodynamic calculations were performed at the 100, 75, and $60 \%$ throttle settings to gain insight into the aerodynamic behavior of the damaged fan and to provide the initial conditions for the unsteady aerodynamic calculations. The characteristic curves of the damaged fan were mapped for each throttle setting by varying the bypass duct static pressure. The bypass duct static pressure was gradually increased to reach an operating point near the operating line that represents operation of the damaged fan installed in a complete engine. Figure 12 provides the fan map of the damaged fan and includes the fan operating line and the characteristic curves corresponding to the 100,75 , and $60 \%$ throttle settings. The values in Fig. 12 are normalized by the undamaged fan operating point at the $100 \%$ throttle setting. It is important to note that the steady calculations converge at a snapshot of the unsteady behavior that may not represent completely the time-averaged behavior of the unsteady

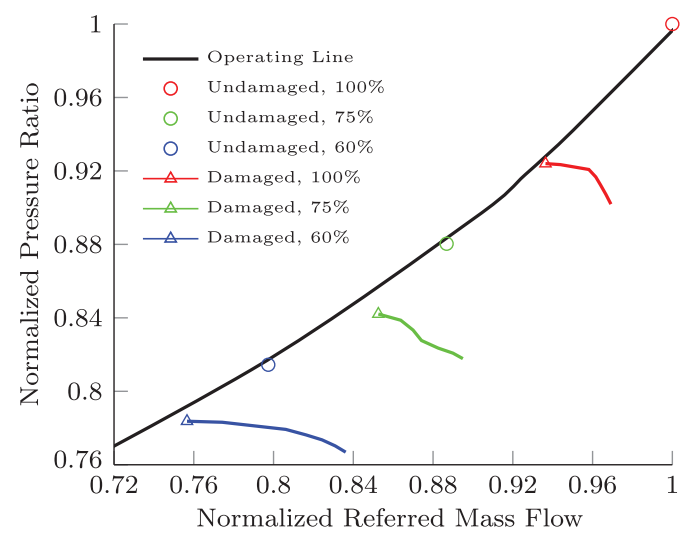

Fig. 12 Damaged fan map for 100, 75, and $60 \%$ throttle settings.

solution. Furthermore, steady-state convergence of the CFD solution at operating points near the operating line was difficult to achieve, indicating that the damaged fan is operating in the vicinity of stall where unsteady flow is dominant. This implies that unsteady flow can influence the aerodynamic behavior of the bird-damaged fan to a significant extent.

The damaged fan map clearly illustrates the significant influence of the bird damage on the steady aerodynamic behavior of the damaged fan. The damaged fan characteristic curves are much flatter near the operating line, indicating that the damaged fan is operating very near the stall point where unsteady flow phenomena may be significant. The operating point of the damaged fan is also significantly affected by the bird damage. Table 2 compares the undamaged and damaged operating points, normalized by the operating point of the undamaged fan at the $100 \%$ throttle setting. Table $\underline{2}$ also provides the percent mass flow loss relative to the undamaged fan at the corresponding throttle setting, where the mass flow loss is related to the thrust loss resulting from the bird strike. To calculate the mass flow loss for the 75 and $60 \%$ throttle settings, the characteristic curve is extrapolated to the operating line assuming a constant pressure ratio (i.e., flat characteristic curve). The largest mass flow loss occurs for the 100 and $60 \%$ throttle settings followed by the $75 \%$ throttle setting.

To gain insight into the flow behavior resulting from the damaged fan sector, the Mach contours at a constant-span circumferential slice of the wheel are examined and compared to the undamaged case. Figure 13 provides Mach number contours of the undamaged and damaged fans at $75 \%$ span (the location of greatest damage) for the $100 \%$ throttle setting. The damaged Mach contours are obtained using the coarse, medium, and fine meshes to demonstrate the mesh sensitivity performed in [26]. The five damaged blades are labeled as 1 through 5, where the blade numbers correspond to those in Fig. 3. When compared with the Mach number contour at $75 \%$ span for the undamaged fan, Figs. 13b-13d clearly illustrate the significant effect of the bird damage on the flowfield. The moderate leading-edge deformation of blade 5 creates a separation bubble on the suction side of the blade that partially blocks the flow through the downstream passage. The larger leading-edge deformation and global bending of blade 2 and blade 4 result in a more substantial flow disruption in

Table 2 Comparison of operating points for the undamaged and damaged fans

\begin{tabular}{lccccc}
\hline \hline $\begin{array}{l}\text { Throttle } \\
\text { setting, } \%\end{array}$ & Configuration & $\begin{array}{c}\text { Normalized } \\
\dot{m}_{R}\end{array}$ & $\begin{array}{c}\text { Normalized } \\
P R\end{array}$ & $\begin{array}{c}\text { Flow } \\
\text { loss, } \%\end{array}$ & $\begin{array}{c}\Delta \text { OL, } \\
\%\end{array}$ \\
\hline 100 & Undamaged & 1.000 & 1.000 & N/A & 0.22 \\
100 & Damaged & 0.931 & 0.933 & 7.33 & 0.63 \\
75 & Undamaged & 0.881 & 0.889 & N/A & 0.70 \\
75 & Damaged & 0.847 & 0.850 & 5.90 & 3.3 \\
60 & Undamaged & 0.793 & 0.822 & N/A & 0.74 \\
60 & Damaged & 0.752 & 0.791 & 7.20 & 2.5 \\
\hline \hline
\end{tabular}

Note: N/A denotes not applicable; OL denotes operating line. 


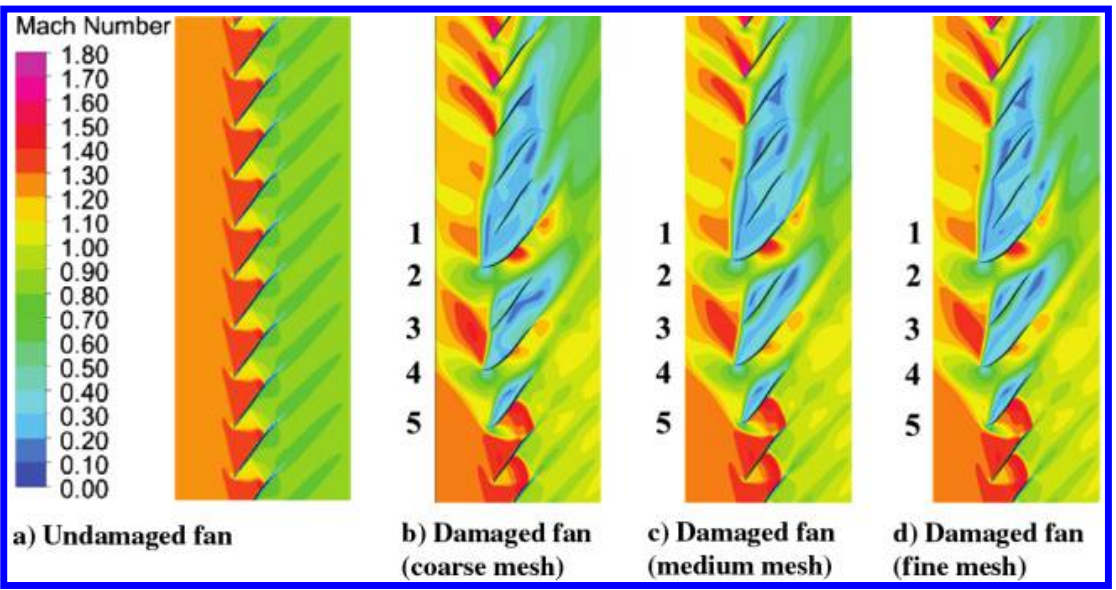

Fig. 13 Comparison of steady Mach number contours of the damaged fan at $75 \%$ span.

which the flow through several downstream passages is blocked. Furthermore, the mass flow through the blade passages downstream of the damaged sector experiences a loss of mass flow due to increased angles of attack and flow separations. However, the passages upstream of the damaged sector compensate for this loss with an increased mass flow and a stronger passage shock.

Figure 14 provides Mach number contours on a constant-axial slice of the wheel at the midblade chord for the undamaged fan and the damaged fan obtained with the coarse, medium, and fine meshes. The significant effect of the damaged sector on the aerodynamic environment of the entire fan wheel is evident. The damaged sector produces stalled flow, identified by the blue regions in Fig. 14, for a large spanwise portion of the damaged blade passages. Stalled flow is also present at the undamaged blade tips over approximately half of the fan wheel. The flow loss associated with the stalled blade tips is compensated by the increased flow through the unstalled blade passages, as is evident from the increased Mach number distribution through these blade passages.

\section{Unsteady Aerodynamic Calculations}

The unsteady aerodynamic calculations for the 100,75 , and $60 \%$ throttle settings are initialized from the corresponding steady solution. A physical time step corresponding to 500 time steps per revolution is specified, and three CFD solver subiterations are performed at each time step for convergence of the solution. The unsteady calculations were performed for 5000 time steps corresponding to 10 revolutions of the fan.

The unsteady operating point is plotted on the fan map in Figs. $15 \mathrm{a}-15 \mathrm{c}$, where the values are normalized by the referred mass flow rate and total pressure ratio of the undamaged fan at the same throttle setting. Considerable unsteadiness in the operating point is evident. For the 100 and $60 \%$ throttle settings, the unsteady operating

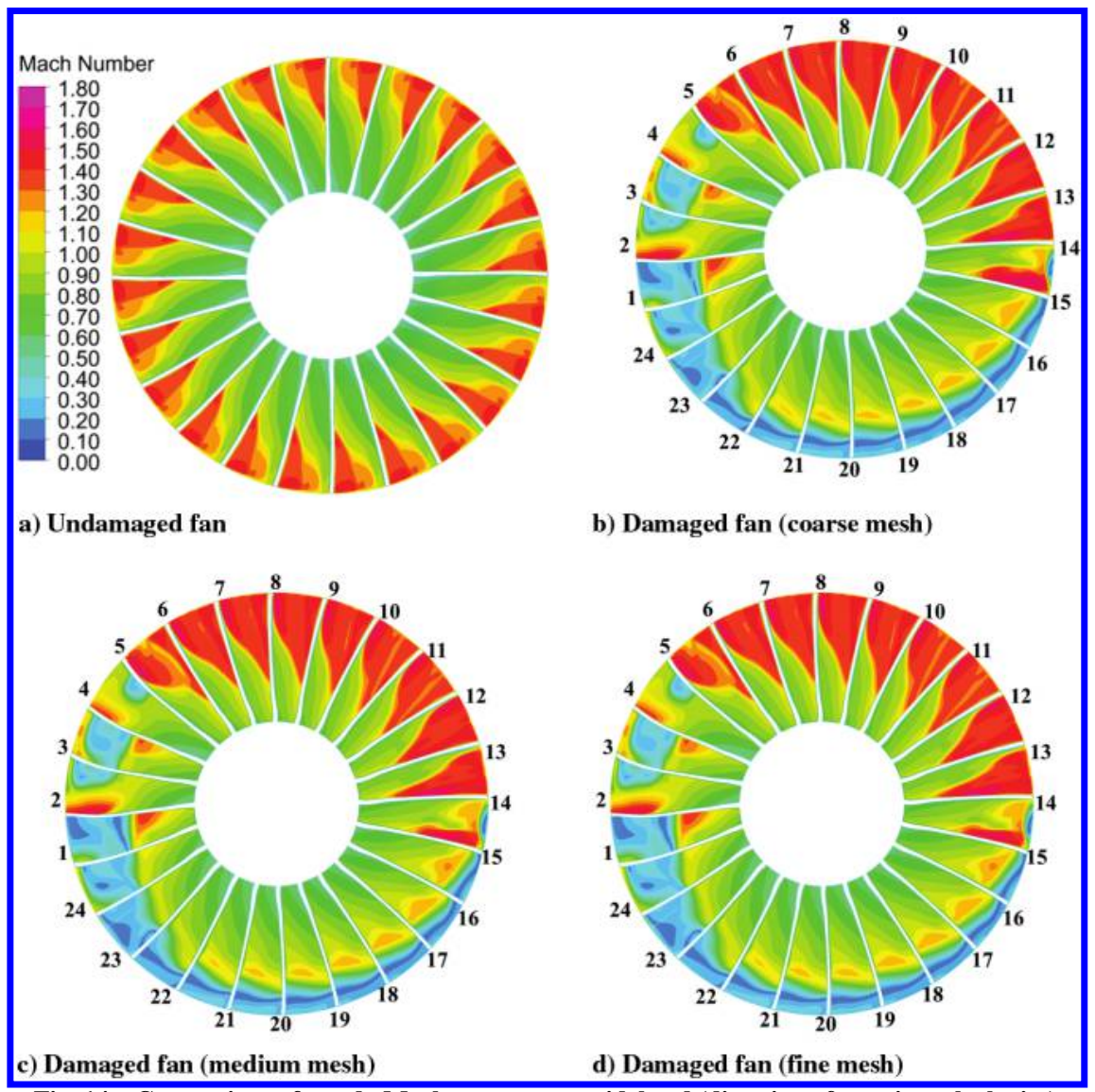

Fig. 14 Comparison of steady Mach contours at midchord (direction of rotation: clockwise). 


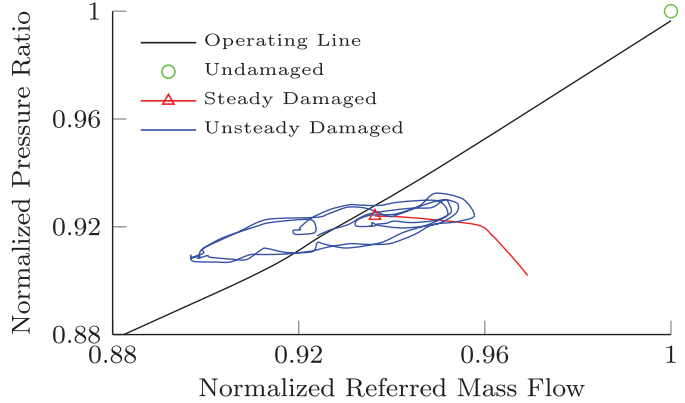

a) Fan map with characteristic curve and steady and unsteady operating points at the $100 \%$ throttle setting

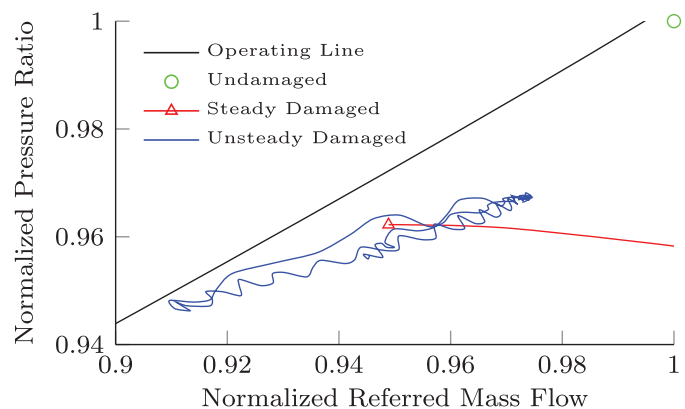

c) Fan map with characteristic curve and steady and unsteady operating points at the $60 \%$ throttle setting

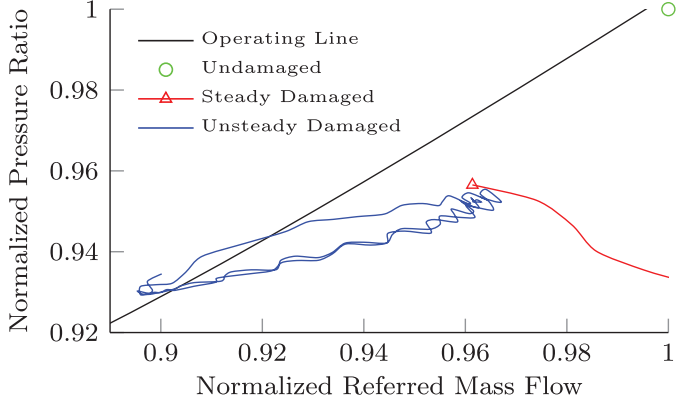

b) Fan map with characteristic curve and steady and unsteady operating points at the $75 \%$ throttle setting

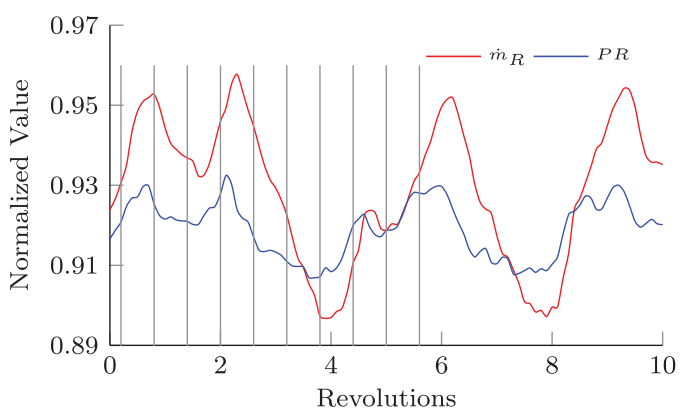

d) Referred mass flow rate and total pressure ratio time history at the $100 \%$ throttle setting

Fig. 15 Unsteady total pressure ratio and referred mass flow rate.

point oscillates about the steady operating point, and the unsteady operating point for the $75 \%$ throttle setting oscillates about a point below the steady value. The mean flow loss is approximately $8 \%$ for each case, and it is greater than that predicted by the steady calculations for the 75 and $60 \%$ throttle settings. Furthermore, the $75 \%$ throttle setting exhibits the largest flow loss of $8.4 \%$ and is considerably greater than the $5.9 \%$ flow loss predicted by the steady solution. Therefore, it is clear that unsteady effects are important in predicting the flow loss of the damaged fan, and the steady aerodynamic calculation of the damaged fan tends to underpredict the flow loss.

Mach contours at midchord are examined to provide insight into the unsteady behavior of the damaged fan. Figure 16 depicts the unsteady Mach number contours at the midchord for 10 equally spaced time steps spanning one representative oscillation of the unsteady solution at the $100 \%$ throttle setting. The corresponding total pressure ratio and referred mass flow rate at these time steps are indicated by the fine vertical lines in Fig. 15d. Only a small amount of unsteadiness is observed in the vicinity of the damaged blades where the flow remains largely separated, and the flow through the damaged blade passages is partially or totally blocked. By contrast, considerable unsteadiness is evident in much of the undamaged sector, with the greatest level of flow unsteadiness occurring in the blade passages between blade 16 clockwise to blade 21 .

The stalled flow emanating from the damaged sector, denoted as a stall cell and identified by the blue regions, is the dominant unsteady flow effect in Fig. 16. At 0.8 revolutions, the stall cell covers roughly one-third of the fan wheel, from blade 21 clockwise to blade 5 , and the mass flow rate is near its maximum. From 1.4 revolutions to 3.8 revolutions, the stall cell regresses slightly before propagating

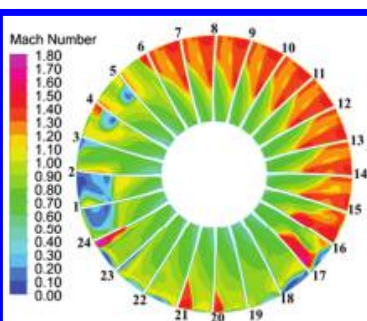

a) 0.2 revolutions

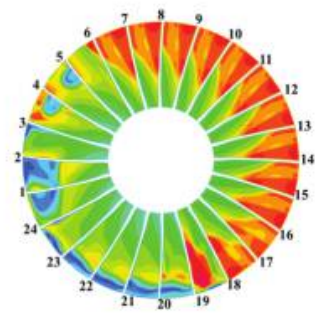

f) 3.2 revolutions

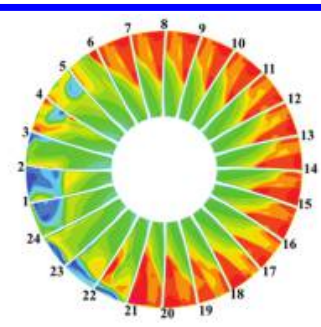

b) 0.8 revolutions

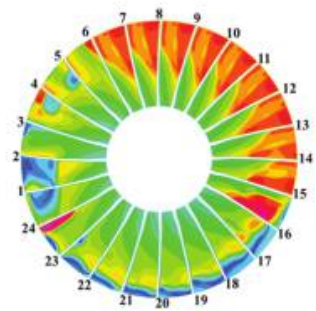

g) 3.8 revolutions

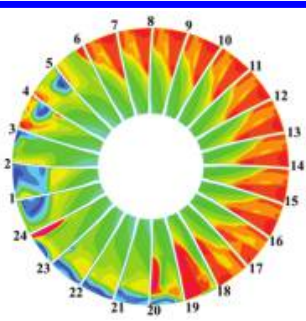

c) 1.4 revolutions

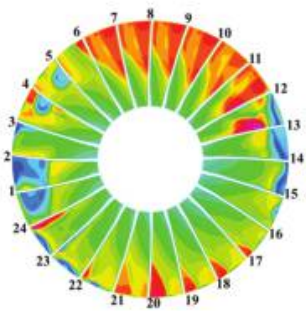

h) 4.4 revolutions

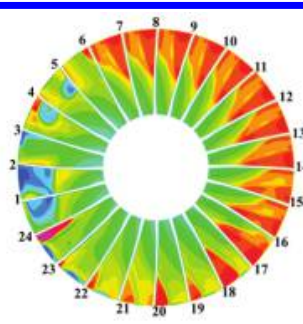

d) 2.0 revolutions

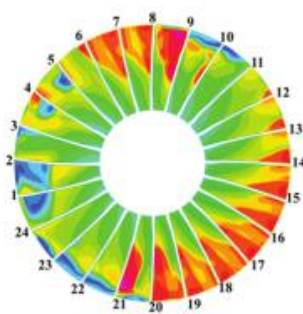

i) 5.0 revolutions

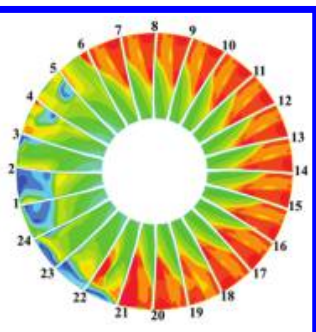

e) 2.6 revolutions

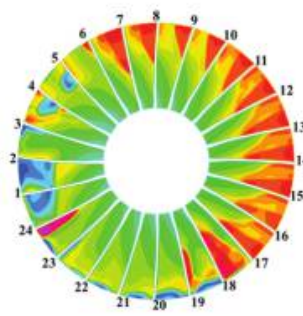

j) 5.6 revolutions

Fig. 16 Unsteady midchord Mach number contours of the damaged fan at the $100 \%$ throttle setting (direction of rotation: clockwise). 
opposite to the direction of rotation until half of the blade tips are stalled, from blade 15 clockwise to blade 5 . At this point, the mass flow rate is at a minimum due to the partially blocked blade passages associated with the stalled flow. Subsequently, from revolution 4.4 to revolution 5.6, the stall cell detaches from the damaged sector, progresses opposite the direction of rotation, and dissipates as the flow recovers and the mass flow rate increases to the maximum value. Furthermore, as the stall cell propagates at the blade tips, the Mach number in the inner span of the corresponding blade passage also decreases, indicating a loss of mass flow through most of the blade passages.

The unsteady Mach contours at 60 and $75 \%$ throttle settings are similar to the $100 \%$ case and are provided in [26]. Similar to the $100 \%$ case, the dominant unsteady property is the stalled flow emanating from the damaged sector. For the 75 and $60 \%$ throttle settings, the stall cell at the blade tips propagates opposite to the direction of rotation until the mass flow rate is at a minimum. As the mass flow rate recovers, the stall cell regresses in the direction of rotation. The stall cell does not detach from the damaged sector, as is the case for the $100 \%$ throttle setting, and the stall cell extends counterclockwise to blade 12. The Mach number of the unstalled blade passages between blades 6 and 11 also varies considerably with the progression and regression of the stall cell.

\section{Forced Response of the Damaged Fan}

The forced response calculations of the bird-damaged fan at the 100,75 , and $60 \%$ throttle settings are presented in this section. The time-dependent aerodynamic loads are extracted from the unsteady CFD calculations and transferred to the structural solver at each time step using the one-way forced response framework. The calculations were performed for 5000 time steps corresponding to 10 revolutions of the fan. The circumferential displacement $u_{\theta} R$ at the blade tip leading edge is used to illustrate the structural response time history. The displacement is calculated relative to the running configuration.

Figure 17a shows the tip displacement for the duration of the forced response calculation at the $100 \%$ throttle setting for four representative blades. Blade 5 represents the responses of damaged blades $1-5$, blade 12 represents the responses of blades $6-14$, blade 18 represents the responses of blades 15-21, and blade 24 represents the responses of blades 22-24. Responses for the remaining blades are available in [26]. The largest tip displacements occur for blades $15-21$, as illustrated by blade 18 , which grow in time and result from the large aerodynamic loads produced by the unsteady stall cell in this region of the fan. The tip displacements for blades 6-14, illustrated by blade 12, exhibit a limited structural response for the first four revolutions until the stall cell releases from the damaged sector and progresses through this region of the fan, producing a sudden increase in tip displacement. The behavior is repeated at $\sim 8$ fan revolutions when a second stall cell is released and progresses through this region. By comparison, blades 22-24, which are located immediately downstream of the damaged sector, exhibit smaller tip displacements that are limited with time, as illustrated by blade 24 in Fig. 17a. Finally, the tip displacements of damaged blades 1-5, illustrated by blade 5 , are the smallest, with blade 4 exhibiting the largest response among the five damaged blades. The most significant structural response occurs for the blades opposite the damaged sector due to the progression of the stall cell.

The circumferential displacements of the blade tips for the 75 and $60 \%$ throttle settings are shown in Figs. $17 \mathrm{~b}$ and $17 \mathrm{c}$ for four representative blades. Blade 4 represents the responses of damaged blades $1-5$, blade 11 represents the responses of blades $6-11$, blade 14 represents the responses of blades $12-19$, and blade 24 represents the responses of blades 20-24. The tip displacements are similar for the two throttle settings. The tip displacements for blades 12-19, illustrated by blade 14 in Figs. $17 \mathrm{~b}$ and $17 \mathrm{c}$, are the greatest and result from the progression and regression of the stall cell in this region of the fan. For both cases, the tip displacement of blade 14 initially exhibits a limited response until the stall cell released from the damaged sector progresses through this region of the fan at $\sim 4.5$ revolutions. Comparing these cases with the $100 \%$ throttle setting, it is evident that the unsteady stall cell does not detach and propagate through undamaged blades 6-11 upstream of the damaged sector. Therefore, the tip displacements of these blades, illustrated by blade 11 , are the smallest and appear to be excited primarily by the cyclic increase and decrease of mass flow through these blade passages. The tip displacements of blades 20-24, which are located immediately downstream of the damaged sector, are illustrated by blade 24 in Figs. $17 \mathrm{~b}$ and $17 \mathrm{c}$. Blade 24 displays a structural response at a higher frequency and smaller amplitude that is induced by the unsteady wake shed from the damaged sector. Finally, the tip displacements of damaged blades $1-5$, illustrated by blade 5 , also exhibit a higherfrequency content. For both cases, blades 3 and 4 display the largest structural response among the damaged blades.

To determine the modal participation in the structural response, the blade displacements are projected onto modal coordinates using Eq. (11). During postprocessing of the structural response, Eq. (11) is solved at each time step using a least-squares approach to determine the generalized degrees of freedom $q_{m}$ corresponding to each mode shape. In this process, the first 10 natural modes of each rotating blade are used and the mode shapes are normalized by the magnitude of the

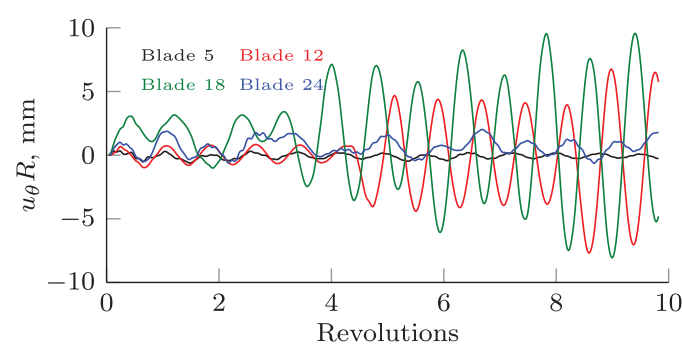

a) $100 \%$ throttle setting

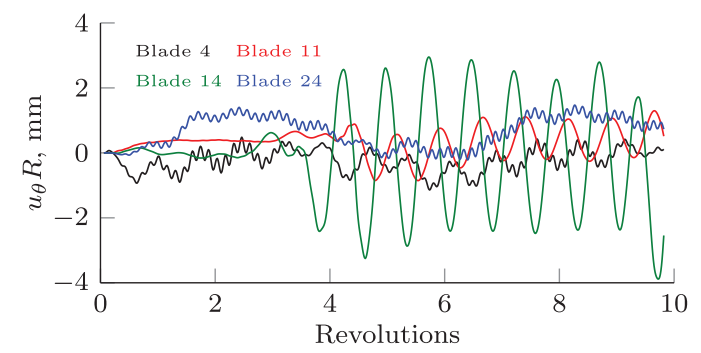

b) $75 \%$ throttle setting

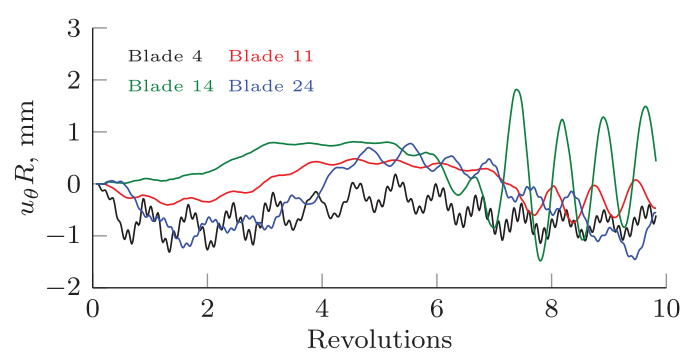

c) $60 \%$ throttle setting

Fig. 17 Tip displacements from the forced response calculations, relative to the steady-state configuration. 
Table 3 Summary of modal contributions of the first five rotating modes for the forced response calculations

\begin{tabular}{lccc}
\hline \hline Blade & $100 \%$ throttle setting & $75 \%$ throttle setting & $60 \%$ throttle setting \\
\hline 1 & $1 \mathrm{~B}^{\mathrm{a}}$ & $1 \mathrm{~B}^{\mathrm{a}}, 2 \mathrm{~T} *$ & $1 \mathrm{~B}^{\mathrm{a}}, 2 \mathrm{~T} *$ \\
2 & $1 \mathrm{~B}^{\mathrm{a}}, 1 \mathrm{~T} \downarrow$ & $1 \mathrm{~B}^{\mathrm{a}}, 2 \mathrm{~T} *, 3 \mathrm{~B} *$ & $1 \mathrm{~B}^{\mathrm{a}}, 1 \mathrm{~T} \downarrow, 3 \mathrm{~B} *, 2 \mathrm{~T} *$ \\
3 & $1 \mathrm{~B}^{\mathrm{a}}, 1 \mathrm{~T} \downarrow, 2 \mathrm{~T} *$ & $1 \mathrm{~B}^{\mathrm{a}}, 2 \mathrm{~T} *^{\mathrm{a}}$ & $1 \mathrm{~B}^{\mathrm{a}}, 2 \mathrm{~T} *$ \\
4 & $1 \mathrm{~B}^{\mathrm{a}}, 1 \mathrm{~T} \downarrow, 2 \mathrm{~T} *$ & $1 \mathrm{~B}^{\mathrm{a}}, 2 \mathrm{~T} *^{\mathrm{a}}, 1 \mathrm{~T} \downarrow, 3 \mathrm{~B} *$ & $1 \mathrm{~B}^{\mathrm{a}}, 2 \mathrm{~T} *^{\mathrm{a}}, 1 \mathrm{~T} \downarrow, 3 \mathrm{~B} *$ \\
5 & $1 \mathrm{~B}^{\mathrm{a}}, 1 \mathrm{~T} \downarrow, 2 \mathrm{~T} *$ & $1 \mathrm{~B}^{\mathrm{a}}, 2 \mathrm{~T} *^{\mathrm{a}}, 1 \mathrm{~T} \downarrow, 3 \mathrm{~B} *$ & $1 \mathrm{~B}^{\mathrm{a}}, 2 \mathrm{~T} *^{\mathrm{a}}, 3 \mathrm{~B} *$ \\
$6-11$ & $1 \mathrm{~B} \uparrow^{\mathrm{a}}$ & $1 \mathrm{~B} \uparrow^{\mathrm{a}}, 2 \mathrm{~B}, 1 \mathrm{~T}$ & $1 \mathrm{~B} \uparrow^{\mathrm{a}}, 2 \mathrm{~B}, 1 \mathrm{~T}$ \\
$12-19$ & $1 \mathrm{~B} \uparrow^{\mathrm{a}}$ & $1 \mathrm{~B} \uparrow^{\mathrm{a}}, 2 \mathrm{~T} *$ & $1 \mathrm{~B} \uparrow^{\mathrm{a}}, 2 \mathrm{~T} *$ \\
20 & $1 \mathrm{~B} \uparrow^{\mathrm{a}}$ & $1 \mathrm{~B}^{\mathrm{a}}, 2 \mathrm{~T} *$ & $1 \mathrm{~B}^{\mathrm{a}}, 2 \mathrm{~T} *$ \\
21 & $1 \mathrm{~B} \uparrow^{\mathrm{a}}$ & $1 \mathrm{~B}^{\mathrm{a}}, 2 \mathrm{~T} *$ & $1 \mathrm{~B}^{\mathrm{a}}, 2 \mathrm{~T} *$ \\
$22-23$ & $1 \mathrm{~B}^{\mathrm{a}}$ & $1 \mathrm{~B}^{\mathrm{a}}, 2 \mathrm{~T} *$ & $1 \mathrm{~B}^{\mathrm{a}}, 2 \mathrm{~T} *$ \\
24 & $1 \mathrm{~B}^{\mathrm{a}}, 2 \mathrm{~T} *$ & $1 \mathrm{~B}^{\mathrm{a}}, 2 \mathrm{~T} *^{\mathrm{a}}$ & $1 \mathrm{~B}^{\mathrm{a}}, 2 \mathrm{~T} *$ \\
\hline \hline
\end{tabular}

leading-edge tip displacement. Subsequently, Eq. (12) is used to calculate the contribution of the $m$ th natural mode to the displacement of any node in the FE mesh:

$$
\begin{gathered}
\boldsymbol{U}(\boldsymbol{x}, t) \approx \sum_{m=1}^{10} q_{m}(t) \Phi_{m}(\boldsymbol{x}) \\
\boldsymbol{U}_{m}(\boldsymbol{x}, t)=q_{m}(t) \Phi_{m}(\boldsymbol{x})
\end{gathered}
$$

Table 3 summarizes the modal contribution of the forced response of blades $1-24$ at each throttle setting. In Table $\underline{3}$, the superscript "a" indicates the dominate modes, downward arrows $(\downarrow)$ indicate a decaying mode, upward arrows $(\uparrow)$ indicate a growing mode, and asterisks $(*)$ indicate a mode for which the amplitude displays beating. Overall, the first bending mode dominates the response of the blades at each throttle setting. In addition, the tip displacements of damaged blades 1-5 contain contributions from the first torsion mode, which decays in time, together with the third bending and second torsion modes that exhibit beating. For the $100 \%$ throttle setting, the response of the undamaged blades is exclusively in the first bending mode, with the exception of blade 24 , which includes a small contribution from the second torsion mode. The first bending mode also dominates the response of the undamaged blades for the 75 and $60 \%$ throttle cases. However, the first torsion and second bending modes also contribute to the response of the upstream undamaged blades, and the second torsion mode displays beating in the region downstream of the damaged blades.

\section{E. Aeroelastic Response of the Damaged Fan}

The aeroelastic response calculations of the bird-damaged fan at 100,75 , and $60 \%$ throttle settings are presented in this section. The aerodynamic and structural models are solved iteratively within each time step using the fully coupled aeroelastic framework. The calculations are performed with 500 time steps per revolution for 10 fan revolutions.

The circumferential displacement at the leading edge of the blade tips is presented in Fig. 18a for the aeroelastic response calculation at the $100 \%$ throttle setting. The displacement is calculated relative to the steady-state configuration, and the responses of blades 5, 12, 18, and 24 represent blades $1-5,6-11,12-19$, and 20-24, respectively. Responses for the remaining blades are available in [26]. The aeroelastic response of the undamaged fan blades resembles the forced response. The largest tip displacements occur for blades 15-21 and grow in time, as illustrated by blade 18 . However, the amplitude of tip displacement for these blades is smaller than that from the forced response calculations. The responses of blades $6-14$, illustrated by blade 12, exhibit a limited response for the first $\sim 3.5$ revolutions until the stall cell releases from the damaged sector and progresses through this region of the fan, producing a sudden increase in tip displacement. After the increase in blade response at $\sim 3.5$ revolutions, the tip displacements decay more rapidly than for the forced response case, indicating that the aeroelastic coupling introduces positive damping for these blades. The response of blades 22-24 displays smaller tip displacements that remain bounded with time, as illustrated by blade 24. When compared to the forced response results in Fig. 17a, the tip displacements for blades 22-24 contain a higher-frequency content, indicating that higher structural modes are participating in the response of these blades. The tip displacements of damaged blades $1-$ 5 , as illustrated by blade 5 in Fig. 18a, are the smallest; however, the aeroelastic response of these blades also contains a higher-frequency component compared to the forced response calculation, shown in Fig. 17a.

The circumferential displacement of the blade tips for the $75 \%$ throttle setting is presented in Fig. 18b. The largest tip displacements occur for blades 12-19 and are due to the stall cell at the blade tips, as illustrated by blade 14. The tip displacements for blades 6-11, illustrated by blade 11 , are larger than those from the forced response

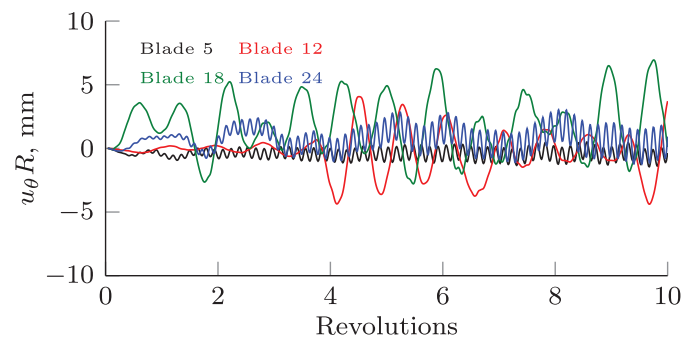

a) $100 \%$ throttle setting

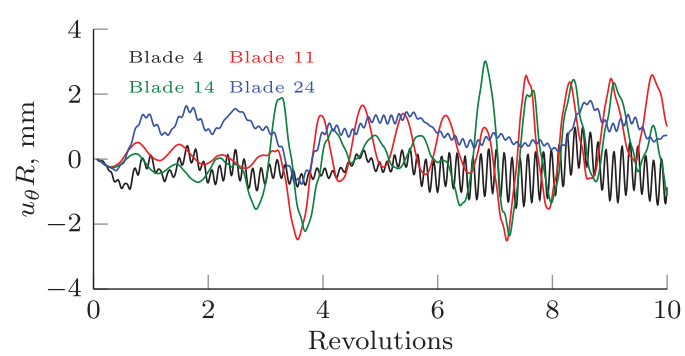

b) $75 \%$ throttle setting

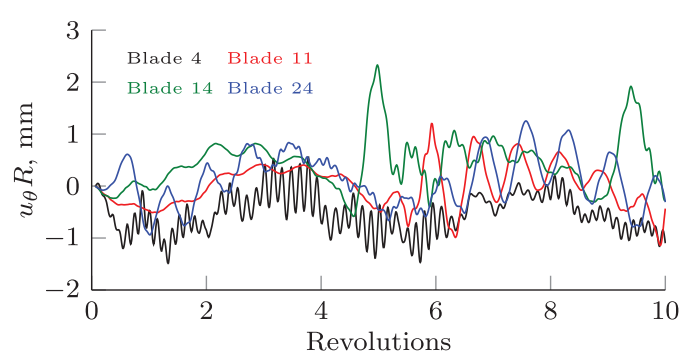

c) $60 \%$ throttle setting

Fig. 18 Tip displacements from the aeroelastic response calculations, relative to the running configuration. 
Table 4 Summary of modal contributions of the first 5 rotating modes for the aeroelastic response calculations

\begin{tabular}{|c|c|c|c|}
\hline Blade & $\begin{array}{l}100 \% \text { throttle } \\
\text { setting }\end{array}$ & $75 \%$ throttle setting & $60 \%$ throttle setting \\
\hline 1 & $1 \mathrm{~B}^{\mathrm{a}}, 2 \mathrm{~T} \uparrow^{\mathrm{a}}$ & $1 \mathrm{~B}^{\mathrm{a}}, 1 \mathrm{~T} \downarrow, 3 \mathrm{~B} \downarrow, 2 \mathrm{~T} *$ & $1 \mathrm{~B}^{\mathrm{a}}, 3 \mathrm{~B} *$ \\
\hline 2 & $1 \mathrm{~B}^{\mathrm{a}}, 3 \mathrm{~B} *, 2 \mathrm{~T} *$ & $1 \mathrm{~B}^{\mathrm{a}}, 3 \mathrm{~B} * \mathrm{a}, 2 \mathrm{~T} *$ & $1 \mathrm{~B}^{\mathrm{a}}, 3 \mathrm{~B} * \mathrm{a}, 2 \mathrm{~B}, 1 \mathrm{~T} \downarrow, 2 \mathrm{~T} *$ \\
\hline 3 & $1 \mathrm{Ba}, 2 \mathrm{~T} \uparrow_{\mathrm{a}}$ & $1 \mathrm{~B}^{\mathrm{a}}, 2 \mathrm{~T} *^{\mathrm{a}}, 1 \mathrm{~T} \downarrow, 3 \mathrm{~B} *$ & $1 \mathrm{~B}^{\mathrm{a}}, 3 \mathrm{~B} *, 2 \mathrm{~T} *$ \\
\hline 4 & $1 \mathrm{~B}^{\mathrm{a}}, 2 \mathrm{~T} *^{\mathrm{a}}$ & $1 \mathrm{~B}^{\mathrm{a}}, 2 \mathrm{~T} \uparrow^{\mathrm{a}} 1 \mathrm{~T} \downarrow, 3 \mathrm{~B} *$ & $1 \mathrm{~B}^{\mathrm{a}}, 3 \mathrm{~B} *^{\mathrm{a}}, 2 \mathrm{~T} *^{\mathrm{a}}, 2 \mathrm{~B}, 1 \mathrm{~T} \downarrow$ \\
\hline 5 & $1 \mathrm{~B}^{\mathrm{a}}, 2 \mathrm{~T} \uparrow^{\mathrm{a}}$ & $1 \mathrm{~B}^{\mathrm{a}}, 2 \mathrm{~T} \uparrow^{\mathrm{a}} 3 \mathrm{~B} *$ & $1 \mathrm{~B}^{\mathrm{a}}, 3 \mathrm{~B} *^{\mathrm{a}}, 1 \mathrm{~T} \downarrow, 2 \mathrm{~T} *$ \\
\hline $6-8$ & $1 \mathrm{~B} \uparrow^{\mathrm{a}}$ & $1 \mathrm{~B} \uparrow_{\mathrm{a}}, 2 \mathrm{~B}, 1 \mathrm{~T}$ & $1 \mathrm{~B} \uparrow, 2 \mathrm{~B}, 1 \mathrm{~T}$ \\
\hline 9 & $1 \mathrm{~B} \uparrow^{\mathrm{a}}$ & $1 \mathrm{~B} \uparrow_{\mathrm{a}}, 2 \mathrm{~B}, 1 \mathrm{~T}$ & $1 \mathrm{~B} \uparrow^{\mathrm{a}}, 2 \mathrm{~B}, 1 \mathrm{~T}, 2 \mathrm{~T}$ \\
\hline $10-11$ & $1 \mathrm{~B} \uparrow^{\mathrm{a}}$ & $1 \mathrm{~B} \uparrow a, 2 \mathrm{~B}, 1 \mathrm{~T}, 2 \mathrm{~T}$ & $1 \mathrm{~B} \uparrow^{\mathrm{a}}, 2 \mathrm{~B}, 1 \mathrm{~T}, 3 \mathrm{~B}, 2 \mathrm{~T}$ \\
\hline 12 & $1 \mathrm{~B} \uparrow^{\mathrm{a}}$ & $1 \mathrm{~B} \uparrow^{\mathrm{a}}$ & $1 \mathrm{~B} \uparrow^{\mathrm{a}}, 3 \mathrm{~B} *^{\mathrm{a}}, 2 \mathrm{~B}, 1 \mathrm{~T}, 2 \mathrm{~T}$ \\
\hline 13 & $1 \mathrm{~B} \uparrow^{a}$ & $1 \mathrm{~B} \uparrow^{\mathrm{a}}, 3 \mathrm{~B} *$ & $1 \mathrm{~B} \uparrow^{\mathrm{a}}, 3 \mathrm{~B} * \mathrm{a}, 2 \mathrm{~B}, 1 \mathrm{~T}$ \\
\hline $14-18$ & $1 \mathrm{~B} \uparrow^{\mathrm{a}}$ & $1 \mathrm{~B} \uparrow^{\mathrm{a}}$ & $1 \mathrm{~B} \uparrow^{\mathrm{a}}, 3 \mathrm{~B} *^{\mathrm{a}}, 2 \mathrm{~B}, 1 \mathrm{~T}$ \\
\hline $19-20$ & $1 \mathrm{~B} \uparrow^{\mathrm{a}}, 2 \mathrm{~T} \uparrow$ & $1 \mathrm{~B} \uparrow^{\mathrm{a}}, 2 \mathrm{~T} *$ & $1 \mathrm{~B} \uparrow^{\mathrm{a}}, 3 \mathrm{~B} *^{\mathrm{a}}, 2 \mathrm{~B}, 1 \mathrm{~T}$ \\
\hline 21 & $1 \mathrm{~B} \uparrow^{\mathrm{a}}, 2 \mathrm{~T} \uparrow$ & $1 \mathrm{~B} \uparrow^{\mathrm{a}}, 2 \mathrm{~T} *$ & $1 \mathrm{~B}^{\mathrm{a}}, 3 \mathrm{~B} *^{\mathrm{a}}, 2 \mathrm{~B}, 1 \mathrm{~T}$ \\
\hline 22 & $1 \mathrm{~B}^{\mathrm{a}}, 2 \mathrm{~T} \uparrow^{\mathrm{a}}$ & $1 \mathrm{~B} \uparrow^{\mathrm{a}}, 2 \mathrm{~T} *$ & $1 \mathrm{~B}^{\mathrm{a}}, 3 \mathrm{~B} *^{\mathrm{a}}, 2 \mathrm{~B}, 1 \mathrm{~T}, 2 \mathrm{~T}$ \\
\hline 23 & $1 \mathrm{~B}^{\mathrm{a}}, 2 \mathrm{~T} \uparrow_{\mathrm{a}}$ & $1 \mathrm{~B} \uparrow \mathrm{a}, 2 \mathrm{~T} *$ & $1 \mathrm{~B}^{\mathrm{a}}, 1 \mathrm{~T}, 2 \mathrm{~B}, 3 \mathrm{~B} \uparrow, 2 \mathrm{~T}$ \\
\hline 24 & $1 \mathrm{~B}^{\mathrm{a}}, 2 \mathrm{~T} \uparrow^{\mathrm{a}}$ & $1 \mathrm{~B} \uparrow^{\mathrm{a}}, 2 \mathrm{~T} *$ & $1 \mathrm{~B}^{\mathrm{a}}, 1 \mathrm{~T}, 2 \mathrm{~B}, 3 \mathrm{~B} \uparrow, 2 \mathrm{~T}$ \\
\hline
\end{tabular}

${ }^{\mathrm{a} D o m i n a n t ~ m o d e s . ~}$

calculations and result from the unsteady stall cell that extends further around the wheel than in the forced response case. The responses of blades 20-24 exhibit a slightly larger structural response compared to the forced response calculations, as illustrated by blade 24 . The tip displacements of damaged blades 1-5, illustrated by blade 4, display a higher-frequency content, indicating the participation of a higher structural modes.

The circumferential displacement of the blade tips for the $60 \%$ throttle setting is presented in Fig. 18c. The largest tip displacements occur for blades $12-19$, as illustrated by blade 14 . The structural response of these blades exhibit a higher-frequency content than the forced response calculations, particularly after the stall cell progresses at $\sim 3.5$ revolutions. Blades $6-11$, illustrated by blade 11 , display limited response until the stall cell detaches and progresses through this region of the fan at $\sim 5.0$ revolutions. When compared to the forced response calculations, the increase in tip displacements is larger and occurs earlier. The structural responses of blades 20-24, illustrated by blade 24 , are similar to the forced response case with the exception of the higher-frequency content that appears after approximately four revolutions. Similar to the aeroelastic response calcula- tions at 100 and $75 \%$ throttle settings, the tip displacements of damaged blades $1-5$, represented by blade 4 , also display a higherfrequency content compared to the forced response.

Table $\underline{4}$ summarized the modal contribution from the aeroelastic response of blades 1-24 at each throttle setting. The first bending mode is dominant in the forced and aeroelastic responses of all blades, with the amplitude of this mode growing for undamaged blades 6-18. The tip displacements from the aeroelastic response also contain increased contributions from higher modes that may be significant and may grow in time or exhibit beating. A comparison of Tables $\underline{3}$ and $\underline{4}$ reveals some fundamental differences between the forced and aeroelastic responses of the damaged fan. For forced response, the primary response of the blade is in the fundamental bending mode, with occasional participation of the higher modes primarily in the second torsion mode. The participation of the higher structural modes is much more evident in the aeroelastic response table, which is reasonable when recognizing that aeroelastic behavior often exhibits a coupled bending-torsion response.

The influence of aeroelastic coupling is illustrated by Figs. 19-21, in which the modal contributions to the forced response and aeroelastic response are compared for one blade at each throttle setting. For the aeroelastic response of blade 24 at the $100 \%$ throttle setting, the second torsion mode grows rapidly in time and dominates the blade response after approximately two fan revolutions, as shown in Fig. 19b. The rapid growth of the second torsion mode is unique to the aeroelastic response and may indicate an aeroelastic instability. For the $75 \%$ throttle case, the influence of aeroelastic coupling is most evident in the aeroelastic response of blade 4 , which exhibits a rapid growth of the second torsion mode, as shown in Fig. 20b. For the $60 \%$ throttle case, the effect of aeroelastic coupling on the circumferential tip displacement is evident by the appearance and increased participation of the third bending mode. This is most noticeable in the aeroelastic response of blade 5, shown in Fig. $21 \mathrm{~b}$, which is dominated by the first bending mode and displays an increased contribution from the third bending mode.

\section{F. Assessment of Aeroelastic Stability}

Determination of the aeroelastic stability of fan blades is complicated due to the inherent unsteadiness of the aerodynamic environment caused by the bird damage. Common approaches to determine the aeroelastic stability of a structure often rely on calculating the aerodynamic damping associated with the growth or

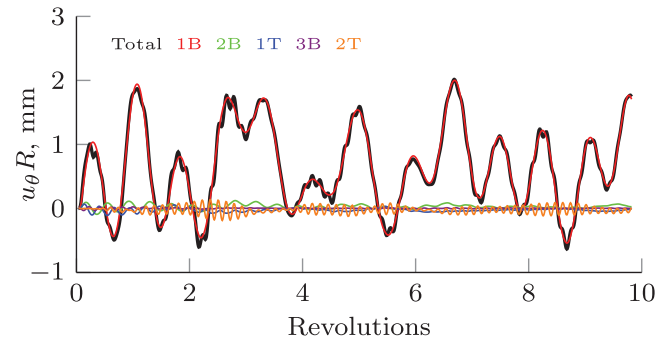

a) Forced response

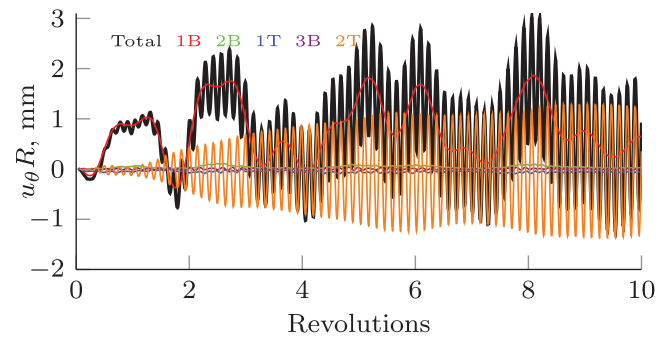

b) Aeroelastic response

Fig. 19 Comparison of blade tip modal contributions of blade 24 at $100 \%$ throttle setting.

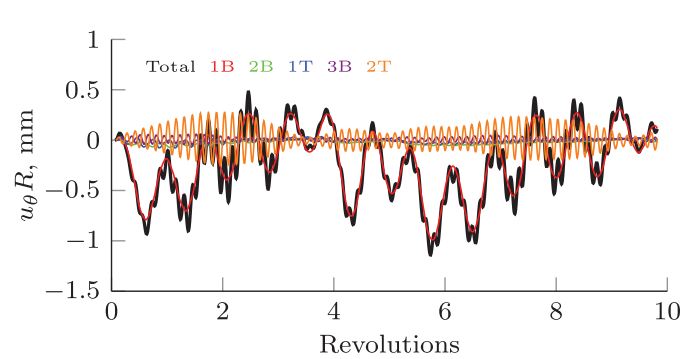

a) Forced response

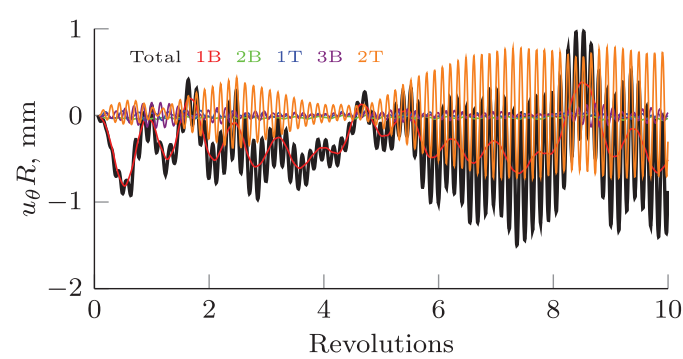

b) Aeroelastic response

Fig. 20 Comparison of blade tip modal contributions of blade 4 at $75 \%$ throttle setting. 


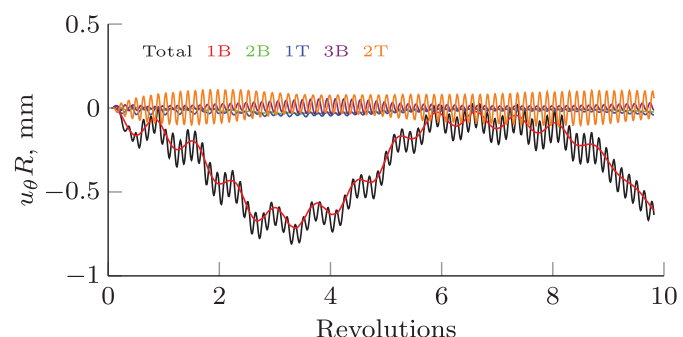

a) Forced response

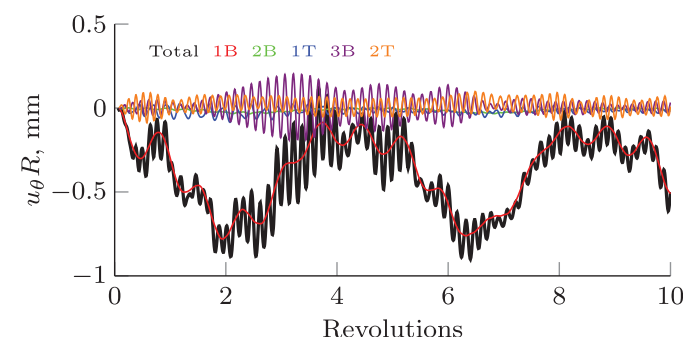

b) Aeroelastic response

Fig. 21 Comparison of blade tip modal contributions of blade 5 at $60 \%$ throttle setting.

decay of the blade response. However, the unsteady aerodynamic loads associated with a bird-damaged fan excite the blades, causing a growth in blade response that may hide the aeroelastic effects.

To provide insight into the cause of the growing blade response in the aeroelastic response behavior, the work performed by the aerodynamic forces on the structure is calculated and compared to the forced response. Aeroelastic stability is inferred from the time history of the aerodynamic work by comparing the aeroelastic and forced response behaviors. Aerodynamic work that grows compared to the forced response indicates a potential aeroelastic instability. Aerodynamic work that decays compared to the forced response calculations implies positive aerodynamic damping. The aerodynamic work of the entire blade is calculated for the forced and aeroelastic responses using Eqs. (13) and (14), respectively:

$$
\begin{gathered}
W_{\mathrm{FR}}(t)=\int_{0}^{t} \boldsymbol{F}_{\text {aero }}(s) \cdot \dot{\boldsymbol{U}}(s) \mathrm{d} s \\
W_{\mathrm{AR}}(t)=\int_{0}^{t} \boldsymbol{F}_{\text {aero }}(s, \boldsymbol{U}, \dot{\boldsymbol{U}}, \ddot{\boldsymbol{U}}) \cdot \dot{\boldsymbol{U}}(s) \mathrm{d} s
\end{gathered}
$$

The aerodynamic work as a function of fan revolutions is presented in Fig. 22 for blades 5, 12, 18, and 24 at the $100 \%$ throttle setting. A comparison of the aerodynamic work from the forced and aeroelastic responses is used to identify potential aeroelastic stabilities. In Fig. 22a, the aerodynamic work on blade 5 from the aeroelastic response is positive and grows at a rate greater than that of the forced response, indicating the potential for aeroelastic instability of the blade. The aerodynamic work for blade 24 from the aeroelastic response displays a behavior that resembles blade 5 , as shown in
Fig. 22d, indicating a possible aeroelastic instability for this blade. For blades 12 and 18, the aerodynamic work from the aeroelastic response does not increase in time when compared to the forced response, as shown in Figs. 22b and 22c. This suggests that the growth in response of these blades is due to the unsteady aerodynamic loads caused by the stall cell, and the aeroelastic effects may introduce positive aerodynamic damping for these blades.

The aerodynamic work at $75 \%$ throttle setting is presented in Fig. 23 for blades 4, 11, 14, and 24. A comparison of the aerodynamic work on blade 4, shown in Fig. 23a, indicates that the growth of the second torsion mode in the aeroelastic response of this blade may be indicative of an aeroelastic instability. For blades 11 and 14, the aerodynamic work from the aeroelastic response is similar to that from the forced response, as shown in Figs. $23 \mathrm{~b}$ and 23c. Therefore, the growth in response of these blades is due to the unsteady aerodynamic loads caused by bird damage rather than an aeroelastic instability. The aerodynamic work from the aeroelastic response for blade 24 , shown in Fig. 23d, is smaller when compared to the forced response. This suggests that aeroelastic effects introduce positive damping, which is evident by the decreased participation of the second torsion mode for the aeroelastic case.

Figure 24 provides the aerodynamic work from the aeroelastic and forced response at the $60 \%$ throttle setting. The aerodynamic work for blade 5 is shown in Fig. 24a. The aerodynamic work from the aeroelastic response increases at a similar rate to the forced response case, which may indicate a neutrally stable case where the blade is at the flutter margin. The aerodynamic work for blades 11, 16, and 22 is shown in Figs. 24b-24d. The aerodynamic work for these blades displays similarity between the aeroelastic and forced response calculations. This behavior suggests two possible situations: 1) neutral stability of the blades, or 2) the blade response is dominated by the unsteady aerodynamic loads induced by the bird damage. Comparison

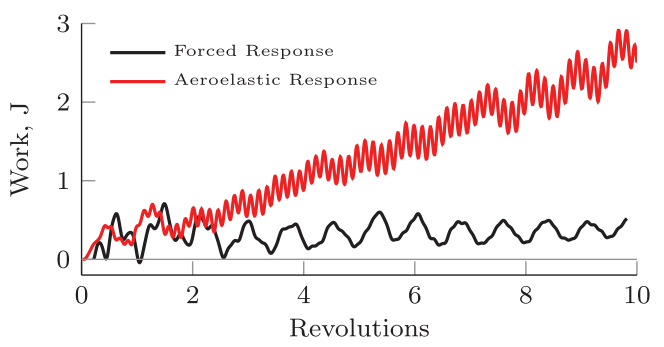

a) Aerodynamic work for blade 5

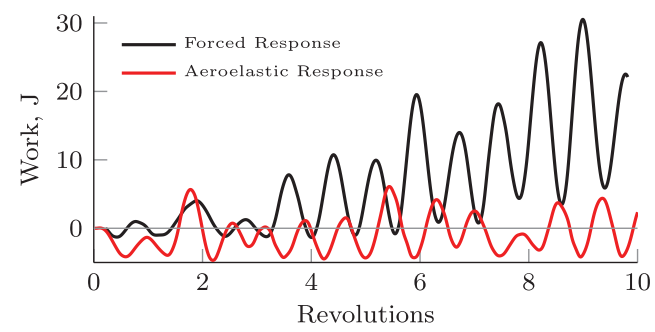

c) Aerodynamic work for blade 18

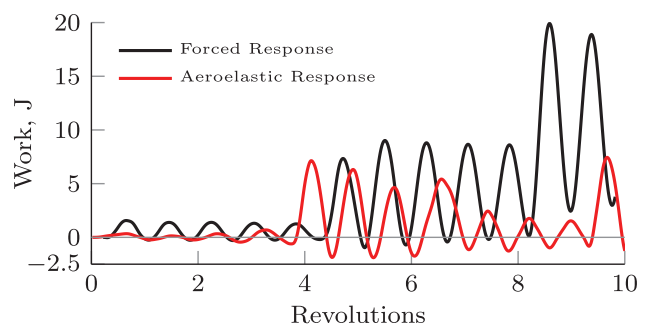

b) Aerodynamic work for blade 12

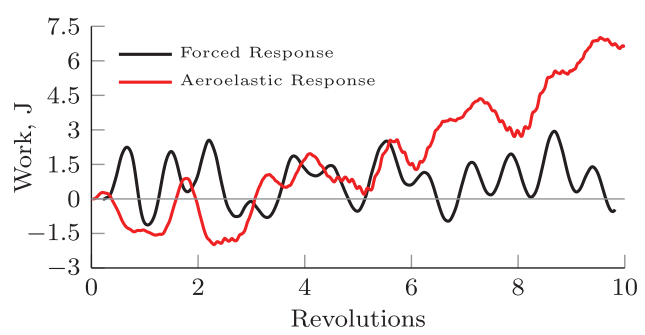

d) Aerodynamic work for blade 24

Fig. 22 Comparison of aerodynamic work from the forced response and aeroelastic response calculations at the $100 \%$ throttle setting. 


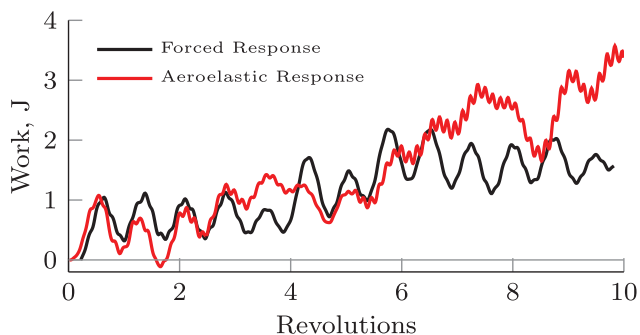

a) Aerodynamic work for blade 4

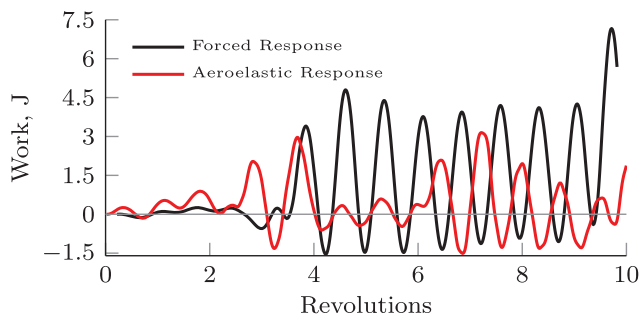

c) Aerodynamic work for blade 14

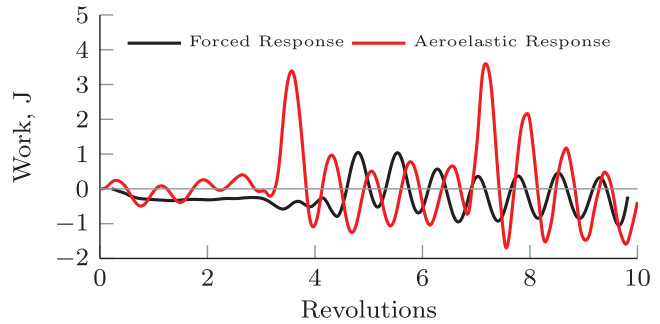

b) Aerodynamic work for blade 11

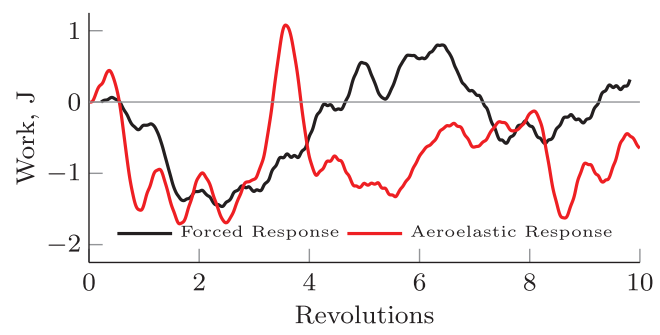

d) Aerodynamic work for blade 24

Fig. 23 Comparison of aerodynamic work from the forced response and aeroelastic response calculations at the $75 \%$ throttle setting.

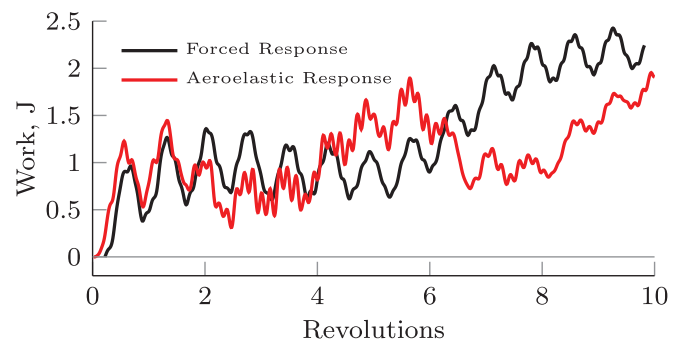

a) Aerodynamic work for blade 4

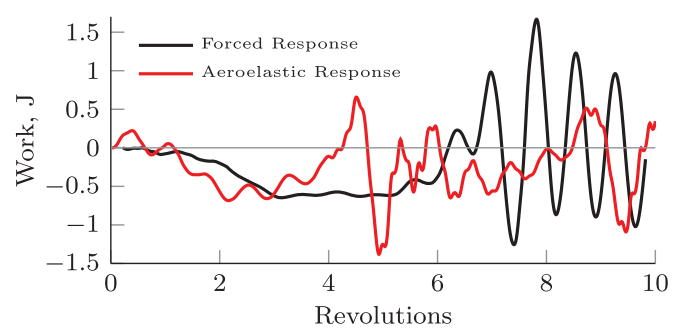

c) Aerodynamic work for blade 14

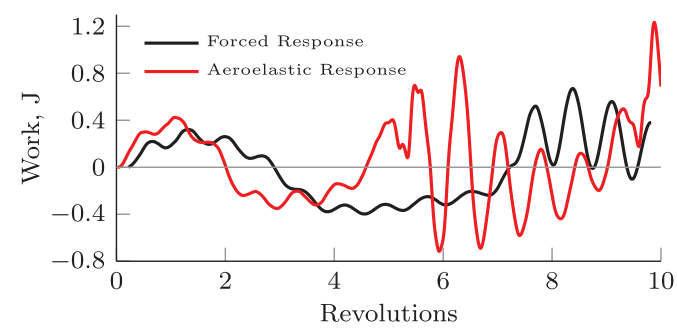

b) Aerodynamic work for blade 11

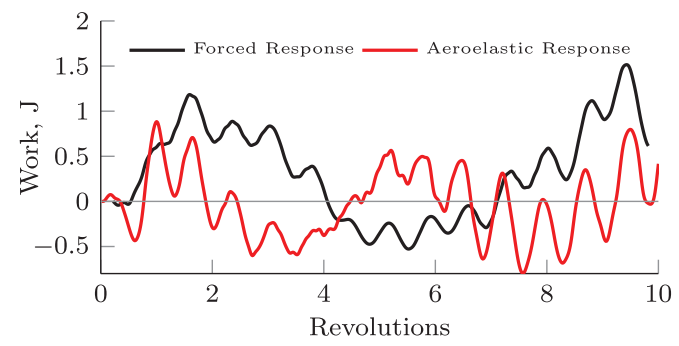

d) Aerodynamic work for blade 24

Fig. 24 Comparison of aerodynamic work from the forced response and aeroelastic response calculations at the $60 \%$ throttle setting.

of the aerodynamic work for the remaining blades at the $60 \%$ throttle setting displays similar behavior and does not indicate potential aeroelastic instabilities. The aeroelastic stability behavior inferred from Figs. 22-24 appears to be reasonable based on physical arguments, since the highest blade loads are at a $100 \%$ throttle setting, and the loading is reduced with the throttle setting.

The results obtained indicate that, for the cases considered, bird damage does not seem to have a major effect on aeroelastic stability. The growth in structural response for the undamaged blades opposite the damaged sector appears to be dominated by the unsteady aerodynamic loads caused by the damaged blades. The damaged blades and those directly downstream of the damaged sector exhibit a possible aeroelastic instability in the second torsion mode for the 100 and $75 \%$ throttle settings. For the case of a $100 \%$ throttle setting, the aeroelastic response indicates an instability dominated by the second torsion mode for blades 3, 5, and 24. By comparison, at a $75 \%$ throttle setting, the aeroelastic response in the second torsion mode of blades 4 and 5 is indicative of an aeroelastic instability. The instability of these blades likely results from interaction between the blade motion and the unsteady wake shed from the upstream damaged blades. The tip displacements of these blades appear to reach a limit-cycle amplitude that is relatively small compared to those of the undamaged blades opposite the damaged sector.

\section{Conclusions}

Predicting the aeroelastic behavior of a bird-damaged fan represents a significant barrier in the development of improved-efficiency turbofan engines. In this study, a coupled CFD/CSD framework is employed to investigate numerically the structural response of a birddamaged fan. A realistic fan configuration is considered that involves a sector of five damaged fan blades obtained through accurate numerical simulation of the bird-strike event. Two computational frameworks are implemented to couple the CFD and CSD components: a one-way forced response framework, which neglects the feedback mechanism of the structural response on the unsteady aerodynamic loading; and a fully coupled aeroelastic response framework that accounts for it. The forced response and aeroelastic response calculations are compared to identify the importance of aeroelastic coupling in predicting the blade structural response. The 
effect of engine rotation is also explored by performing the calculations at the 100,75 , and $60 \%$ throttle settings, which correspond to FAA certification requirements for bird strike.

This study represents the first comprehensive investigation of the aeroelastic behavior of a bird-damaged wide-chord fan stage. Thus, it makes an important contribution to the state of the art in turbofan aeroelasticity. The primary goal was to predict the structural response of the fan blades and investigate the importance of aeroelastic coupling. Overall, the results emphasize several important characteristics of the damaged fan, which are summarized as follows:

1) The unsteady stall cell emanating from the damaged sector produces large unsteady aerodynamic loads that drive the blade response. At the $100 \%$ throttle setting, the stall cell detaches from the damaged sector and excites a majority of the blades. In contrast, the stall cell does not detach for the 75 and $60 \%$ throttle settings, and the undamaged blades upstream of the damaged sector are unaffected by the unsteady stall cell.

2) For all throttle settings considered, the undamaged blades opposite the damaged sector exhibit the largest response for both the forced response and aeroelastic response calculations. This provides important physical insight in to the response of the bird-damaged fan excitation and emphasizes the importance of modeling the entire fan wheel.

3) Comparison of the aerodynamic work from the forced and aeroelastic responses is useful for identification of the mechanism driving the response. It also allows one to assess the aeroelastic stability of the bird-damaged fan.

4) The results indicate that the growth in blade response results primarily from the unsteady aerodynamic loads caused by the damaged fan blades rather than by an aeroelastic mechanism. This implies that aeroelastic effects are secondary to the forced response effects caused by the unsteady stall cell.

5) The aeroelastic responses of the damaged blades and those immediately counterclockwise from the damaged sector exhibit rapid growth that may be associated with aeroelastic instability of higher structural modes. The aeroelastic response at the 100 and $75 \%$ throttle settings show increased participation of the second torsion mode, particularly for the damaged blades and those directly downstream of the damaged sector. The $60 \%$ throttle setting calculations indicate an increased participation of the third bending mode for the damaged blades and those opposite the damaged sector.

Although this study demonstrates the feasibility of performing aeroelastic response calculations of a bird-damaged fan, the computations require a significant investment in time that may prevent practical implementation for design purposes. The results show that the forced response approach, which is computationally less expensive, may be sufficient for predicting the approximate blade response. Thus, the forced response may have a useful role in preliminary design of fans under bird-strike conditions with the understanding that the forced response neglects the effects of aerodynamic damping. In addition, these results were calculated assuming that structural damping is neglected. Including structural damping in the structural dynamic model may reduce or eliminate the aeroelastic instability noted. Experimental results on damaged fan blade sectors caused by bird strike are not available in the open literature. Therefore, comparison of the results obtained from this computational study with experimental data is not practical. However, it is hoped that similar numerical studies will be useful for verifying the conclusions obtained.

\section{References}

[1] Teichmann, H. C., and Tadros, R. N., "Analytical and Experimental Simulation of Fan Blade Behavior and Damage Under Bird Impact," Journal of Engineering for Gas Turbines and Power, Vol. 113, No. 4, Oct. 1991, pp. 582-594. doi: $10.1115 / 1.2906281$

-[2] Horsley, J., "The 'Rolls-Royce' Way of Validating Fan Integrity," AIAA/ SAE/ASME/ASEE 29th Joint Propulsion Conference and Exhibit, AIAA Paper 1993-2602, June 1993, pp. 1-22.

-[3] Isomura, K., and Giles, M. B., "A Numerical Study of Flutter in a Transonic Fan," Journal of Turbomachinery, Vol. 120, No. 3, July 1998, pp. 500-507.

doi:10.1115/1.2841746

[4] "Bird Ingestion," Aeronautics and Space, Federal Aviation Administration, Dept. of Transportation, Title 14, Code of Federal Regulations $33.76,2013$

[5] Bendiksen, O. O., "Aeroelastic Problems in Turbomachines," Transactions of the ASME, Vol. 113, Oct. 1991, pp. 582-594.

[6] Bendiksen, O. O., Kielb, R. E., and Hall, K. C., "Structural Technology," Encyclopedia of Aerospace Engineering, Turbomachinery Aeroelasticity, Vol. 3, Wiley, New York, 2010, pp. 1625-1639.

[7] Goyal, V. K., Huertas, C. A., Borrero, J. R., and Leutwiler, T. R., "Robust Bird-Strike Modeling Based on ALE Formulation Using LS-DYNA," 47th AIAA/ASME/ASCE/AHS/ASC Structures, Structural Dynamics, and Materials Conference, AIAA Paper 2006-1759, May 2006.

[8] Hirschbein, M. S., "Bird Impact Analysis Package for Turbine Engine Fan Blades," 23rd AIAA/ASME/ASCE/AHS/ASC Structures, Structural Dynamics, and Materials Conference, AIAA Paper 1982-696, May 1982.

[9] Mao, R., Meguid, S. A., and Ng, T. Y., "Finite Element Modeling of a Bird Striking an Engine Fan Blade," Journal of Aircraft, Vol. 44, No. 2, 2007, pp. 583-596.

doi: $10.2514 / 1.24568$

[10] Mao, R., Meguid, S. A., and Ng, T. Y., "Transient Three Dimensional Finite Element Analysis of a Bird Striking a Fan Blade," International Journal of Mechanics and Materials in Design, Vol. 4, No. 1, 2008, pp. 79-96.

doi:10.1007/s10999-008-9067-1

[11] Meguid, S. A., Mao, R., and Ng, T. Y., "FE Analysis of Geometry Effects of an Artificial Bird Striking an Aeroengine Fan Blade," International Journal of Impact Engineering, Vol. 35, No. 6, 2008, pp. 487-498. doi:10.1016/j.ijimpeng.2007.04.008

[12] Nizampatnam, L. S., and Horn, W. J., "Investigation of Equation of State Models for Predicting Bird Impact Loads," 46th AIAA Aerospace Sciences Meeting and Exhibit, AIAA Paper 2008-0682, Jan. 2008.

[13] Shimamura, K., Shibue, T., and Grosch, D. J., "Numerical Simulation of Bird Strike Damage on Jet Engine Fan Blade," Proceedings of the ASME/JSME Pressure Vessels and Piping Conference, American Soc. of Mechanical Engineers PVP2004-2867, Fairfield, NJ, pp. 161-166, July 2004. doi: 10.1115/PVP2004-2867

[14] Imregun, M., and Vahdati, M., "Aeroelastic Analysis of a Bird-Damaged Fan Assembly Using a Large Numerical Model," Aeronautical Journal, Vol. 103, No. 1030, Dec. 1999, pp. 569-578.

[15] Kim, M., Vahdati, M., and Imregun, M., "Aeroelastic Stability Analysis of a Bird-Damaged Aeroengine Assembly," Journal of Aerospace Sciences and Technologies, Vol. 5, No. 7, 2001, pp. 469-482. doi:10.1016/S1270-9638(01)01122-1

[16] Aotsuka, M., and Tsuchiya, N., "Numerical Simulation of Transonic Fan Flutter with 3-D N-S CFD Code," Proceedings of the ASME Turbo Expo 2008: Power for Land, Sea, and Air, American Soc. of Mechanical Engineers GT2008-50573, Fairfield, NJ, June 2008, pp. 723-734. doi:10.1115/GT2008-50573

[17] Marshall, J. G., and Imregun, M., "A Review of Aeroelasticity Methods with Emphasis on Turbomachinery Applications," Journal of Fluids and Structures, Vol. 10, No. 3, 1996, pp. 237-267. doi:10.1006/jfls.1996.0015

[18] Bartels, R. E., and Sayma, A. I., "Computational Aeroelastic Modelling of Airframes and Turbomachinery: Progress and Challenges," Philosophical Transactions of the Royal Society of London, Series A: Mathematical and Physical Sciences, Vol. 365, No. 1859, Oct. 2007, pp. 2469-2499. doi:10.1098/rsta.2007.2018

- [19] Verdon, J., "Review of Unsteady Aerodynamic Methods for Turbomachinery Aeroelastic and Aeroacoustic Applications," AIAA Journal, Vol. 31, No. 2, Feb. 1993, pp. 235-250. doi: $10.2514 / 3.11660$

[20] Bendiksen, O. O., "Modern Developments in Computational Aeroelasticity," Journal of Aerospace Engineering, Vol. 218, No. 3, 2004, pp. 157-177

[21] Bohari, B., and Sayma, A., "CFD Analysis of Effects of Damage Due to Bird Strike on Fan Performance," Proceedings of the ASME Turbo Expo 2010: Power for Land, Sea, and Air, American Soc. of Mechanical Engineers GT2010-22365, Fairfield, NJ, June 2010, pp. 173-181. doi:10.1115/GT2010-22365

[22] Muir, E. R., and Friedmann, P. P., "Aeroelastic Response of BirdDamaged Fan Blades Using a Coupled CFD/CSD Framework," 55th AIAA/ASME/ASCE/AHS/ASC Structures, Structural Dynamics, and Materials Conference, AIAA Paper 2014-0334, Jan. 2014. 
[23] Muir, E. R., and Friedmann, P. P., "Unsteady Aerodynamic Loading on Bird-Damaged Fan Blades and Its Effect on Forced Response," 2013 International Forum on Aeroelasticity and Structural Dynamics, Bristol, U.K., June 2013.

[24] Muir, E. R., and Friedmann, P. P., "Unsteady Aerodynamic Analysis of a Bird-Damaged Turbofan," 54th AIAA/ASME/ASCE/AHS/ASC Structures, Structural Dynamics, and Materials Conference, AIAA Paper 2013-1773, April 2013.

[25] Ansys CFX-Solver Theory Guide - Version 14.5, ANSYS, Inc., Canonsburg, PA, 2012.

[26] Muir, E. R., "Aeroelastic Behavior of Bird-Damaged Fan Blades Using a Coupled CFD/CSD Framework," Ph.D. Thesis, Dept. of Aerospace Engineering, Univ. of Michigan, Ann Arbor, MI, 2014.

[27] Thompson, K. W., "Time Dependent Boundary Conditions for Hyperbolic Systems II," Journal of Computational Physics, Vol. 89, No. 2, 1990, pp. 439-461. doi:10.1016/0021-9991(90)90152-Q

[28] Poinsot, T. J., and Lele, S. K., "Boundary Conditions for Direct Simulations of Compressible Viscous Flows," Journal of Computational Physics, Vol. 101, No. 1, 1992, pp. 104-129. doi:10.1016/0021-9991(92)90046-2

[29] Morris, A., Allen, C., and Rendall, T., "CFD-Based Optimization of Aerofoils Using Radial Basis Functions for Domain Element Parameterization and Mesh Deformation," International Journal for Numerical Methods in Fluids, Vol. 58, No. 8, 2008, pp. 827-860. doi:10.1002/fld.v58:8

[30] van Zuijlen, A., de Boer, A., and Bijl, H., "Higher-Order Time Integration Through Smooth Mesh Deformation for 3D Fluid-Structure
Interaction Simulations," Journal of Computational Physics, Vol. 224, No. 1, 2007, pp. 414-430. doi:10.1016/j.jcp.2007.03.024

[31] Jakobsson, S., and Amoignon, O., "Mesh Deformation Using Radial Basis Functions for Gradient Based Aerodynamic Shape Optimization," Computers and Fluids, Vol. 36, No. 6, 2007, pp. 1119-1136. doi:10.1016/j.compfluid.2006.11.002

[32] Buhmann, M. D., Radial Basis Functions: Theory and Implementations, Cambridge Univ. Press, Cambridge, MA, 2003, pp. 99-162.

[33] de Boer, A., van der Schoot, M., and Bijl, H., "Mesh Deformation Based on Radial Basis Function Interpolation," Computers and Structures, Vol. 85, No. 11, 2007, pp. 784-795. doi:10.1016/j.compstruc.2007.01.013

[34] Lamorte, N., and Friedmann, P. P., "Hypersonic Aeroelastic Stability Boundary Computations using Radial Basis Functions for Mesh Deformation," 18th AIAA/3AF International Space Planes and Hypersonic Systems and Technologies Conference, AIAA Paper 2012-5943, Sept. 2012.

[35] Mechanical APDL Theory Reference Guide - Version 14.5, ANSYS, Inc., Canonsburg, PA, 2012.

[36] Hilber, H. M., Hughes, T. J. R., and Taylor, R. L., "Improved Numerical Dissipation for Time Integration Algorithm in Structural Dynamics," Earthquake Engineering and Structural Dynamics, Vol. 5, No. 3, JulySept. 1977, pp. 283-292. doi:10.1002/(ISSN)1096-9845

[37] Mechanical APDL Coupled-Field Analysis Guide - Version 14.5, ANSYS, Inc., Canonsburg, PA, 2012. 